\title{
Modelling and optimization of factors influencing adsorptive performance of agrowaste-derived Nanocellulose Iron Oxide Nanobiocomposites during remediation of Arsenic contaminated groundwater
} DOI:

10.1016/j.ijbiomac.2020.07.113

Document Version

Accepted author manuscript

Link to publication record in Manchester Research Explorer

Citation for published version (APA):

Baruah, J., Chaliha, C., Kalita, E., Nath, B. K., Field, R. A., \& Deb, P. (2020). Modelling and optimization of factors influencing adsorptive performance of agrowaste-derived Nanocellulose Iron Oxide Nanobiocomposites during remediation of Arsenic contaminated groundwater. International Journal of Biological Macromolecules, 164, 53-65. https://doi.org/10.1016/j.ijbiomac.2020.07.113

Published in:

International Journal of Biological Macromolecules

\section{Citing this paper}

Please note that where the full-text provided on Manchester Research Explorer is the Author Accepted Manuscript or Proof version this may differ from the final Published version. If citing, it is advised that you check and use the publisher's definitive version.

\section{General rights}

Copyright and moral rights for the publications made accessible in the Research Explorer are retained by the authors and/or other copyright owners and it is a condition of accessing publications that users recognise and abide by the legal requirements associated with these rights.

\section{Takedown policy}

If you believe that this document breaches copyright please refer to the University of Manchester's Takedown Procedures [http://man.ac.uk/04Y6Bo] or contact uml.scholarlycommunications@manchester.ac.uk providing relevant details, so we can investigate your claim.

\section{OPEN ACCESS}


Modelling and optimization of factors influencing adsorptive performance of agrowastederived Nanocellulose/Iron Oxide Nanobiocomposites during remediation of Arsenic contaminated groundwater

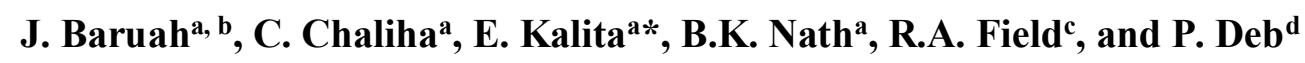

a'Department of Molecular Biology and Biotechnology, Tezpur University, Tezpur, Assam, 784028, India

${ }^{b}$ Department of Chemical Sciences, Tezpur University, Tezpur, Assam, 784028, India

${ }^{c}$ Department of Chemistry and Manchester Institute of Biotechnology The University of

manchester 131 Princess Street, Manchester M1 7DN (UK)

${ }^{\mathrm{d}}$ Department of Physics, Tezpur University, Tezpur, Assam, 784028, India

*Correspondence:

Dr. Eeshan Kalita

ekalita@tezu.ernet.in

\section{Highlights:}

- Nanocellulose based superparamagnetic adsorbents developed for $\sim 99 \%$ As removal

- CCD-based RSM and MLP-based ANN models used for modelling and optimizing As removal

- Kinetic studies suggest chemisorptive removal of As

- Adsorbents are recyclable and better than commercial adsorbents

- Adsorbents effective for removal of As from contaminated groundwater 
Modelling and optimization of factors influencing adsorptive performance of agrowastederived Nanocellulose/Iron Oxide Nanobiocomposites during remediation of Arsenic contaminated groundwater

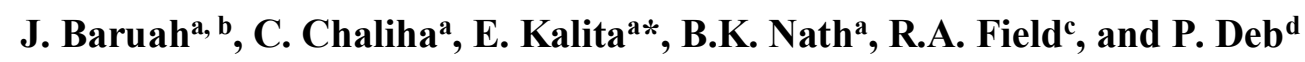

${ }^{\text {a} D e p a r t m e n t ~ o f ~ M o l e c u l a r ~ B i o l o g y ~ a n d ~ B i o t e c h n o l o g y, ~ T e z p u r ~ U n i v e r s i t y, ~ T e z p u r, ~ A s s a m, ~}$ 784028, India

${ }^{\mathrm{b}}$ Department of Chemical Sciences, Tezpur University, Tezpur, Assam, 784028, India

${ }^{\mathrm{c}}$ Department of Chemistry and Manchester Institute of Biotechnology The University of manchester 131 Princess Street, Manchester M1 7DN (UK)

${ }^{\mathrm{d} D e p a r t m e n t ~ o f ~ P h y s i c s, ~ T e z p u r ~ U n i v e r s i t y, ~ T e z p u r, ~ A s s a m, ~ 784028, ~ I n d i a ~}$

\section{*Correspondence:}

Dr. Eeshan Kalita

ekalita@tezu.ernet.in

\section{Abstract}

Nanocellulose/Iron Oxide Nanobiocomposites (NIONs) were synthesized from rice husk and sugarcane bagasse derived nanocelluloses for adsorptive removal of arsenic and associated contaminants present in groundwater samples. These NIONSs were superparamagnetic, hence magnetically recoverable and demonstrated promising recyclability. Synthesis of NIONs was confirmed by Transmission electron microscopy (TEM), X-Ray Diffraction (XRD), Fourier transform infrared spectroscopy (FTIR) and X-ray photoelectron spectroscopic (XPS). FTIR and XPS data together with adsorption kinetics provide insights into probable adsorption mechanism of Arsenic by NIONs. The experimental conditions for 10 different variants were modelled using response surface methodology (RSM) based on central composite design (CCD), considering the 
parameters; adsorbate dosage, adsorbent dosage, $\mathrm{pH}$ and contact time. The results identified the best performing variants and the optimal conditions for maximal absorption ( $\sim 99 \%)$. These results were validated using a three-layer feed-forward Multilayer Perceptron (MLP) based Artificial Neural Network (ANN) model. Both RSM and ANN chemometric models were in close conformity for optimized conditions of highest adsorption by specific variants. The standardized conditions were used to expand the study to field-based arsenic contaminated groundwater samples and their performance to commercial adsorbents. NIONs show promising commercial potential for water remediation applications due to their high adsorptive performance, magnetic recoverability and recyclability. 
1 Modelling and optimization of factors influencing adsorptive performance of agrowaste-derived

\section{Nanocellulose/Iron Oxide Nanobiocomposites during remediation of Arsenic contaminated groundwater}

3 J. Baruah ${ }^{a, b}$, C. Chaliha ${ }^{a}$, E. Kalita ${ }^{a *}$, B.K. Nath ${ }^{a}$, R.A. Field ${ }^{c}$, and P. Deb ${ }^{d}$

$4 \quad{ }^{a}$ Department of Molecular Biology and Biotechnology, Tezpur University, Tezpur, Assam, 784028, India

$5 \quad$ bepartment of Chemical Sciences, Tezpur University, Tezpur, Assam, 784028, India

6 'Department of Chemistry and Manchester Institute of Biotechnology The University of manchester 131 Princess Street, Manchester M1 7DN (UK)

$8 \quad$ d Department of Physics, Tezpur University, Tezpur, Assam, 784028, India

$9 \quad *$ Correspondence:

10

11 Dr. Eeshan Kalita

12 ekalita@tezu.ernet.in

\section{Abstract}

15 Nanocellulose/Iron Oxide Nanobiocomposites (NIONs) were synthesized from rice husk and sugarcane bagasse derived nanocelluloses for adsorptive removal of arsenic and associated contaminants present in groundwater samples. These NIONSs were superparamagnetic, hence magnetically recoverable and demonstrated promising recyclability. Synthesis of NIONs was confirmed by Transmission electron microscopy (TEM), X-Ray Diffraction (XRD), Fourier transform infrared spectroscopy (FTIR), and X-ray photoelectron spectroscopic (XPS). FTIR and XPS data together with adsorption kinetics provide insights into probable adsorption mechanism of Arsenic by NIONs. The experimental conditions for 10 different variants were modelled using response surface methodology (RSM) based on central composite design (CCD), considering the parameters; adsorbate dosage, adsorbent dosage, $\mathrm{pH}$, and contact time. The results identified the best performing variants and the optimal conditions for maximal absorption ( $99 \%$ ). These results were validated using a three-layer feed-forward Multilayer Perceptron (MLP) based Artificial Neural Network (ANN) model. Both RSM and ANN chemometric models were in close conformity for optimized conditions of highest adsorption by specific variants. The standardized conditions were used to expand the study to field-based arsenic contaminated groundwater samples and their performance to commercial adsorbents. NIONs show promising commercial potential for water remediation applications due to their high adsorptive performance, magnetic recoverability and recyclability. Keywords: Nanobiocomposite; Remediation; Chemometric model

\section{Introduction}

Groundwater contamination with arsenic (As) represents emergent health and environmental issue worldwide due to the high toxicity of As that have been found at chronic levels in most countries (e.g., China, India, Indonesia, Pakistan, Bangladesh, USA, Hungary, Canada, Brazil, and Taiwan) [1, 2]. World Health Organization (WHO) has strictly limited the Maximum Contaminant Level (MCL) of As in drinking water to $10 \mu \mathrm{gL}^{-}$

${ }^{1}$ [3]. Therefore, removal of As from contaminated water to meet the drinking water standards is been perused fervently. A variety of treatment processes such as precipitation [4], membrane filtration [5], electro-coagulation [6], adsorption [7], and ion-exchange [8] are available to reduce As concentration in water. However, their high operational costs along with the production of toxic sludge are important factors that should be 
considered before the section of treatment method. In this context, biosorption using low-cost biosorbents derived from abundant renewable resources has seen promising advancement to remove As from water thus proving a sustainable and eco-friendly solution [9, 10].

37 Over the past few years, the use of biomaterials such as cellulose, chitosan, chitin, starch, gelatin and alginate for water remediation has the advantages of biocompatibility and non-toxicity compared with non-biological adsorbents [11]. Among such biomaterials, cellulose has superior advantages of being renewable, biodegradable, biophilic, large abundance in nature, and low cost [11, 12]. Since it has a large number of hydroxyl groups, natural cellulose has excellent adsorption properties for harmful metal ions [13]. However, cellulose also forms an unstable complex between the $\beta$-D-glucose unit and heavy metal ions, reducing the adsorption capacity and limiting its potential. To overcome this limitation different approaches have been reported to date $[\mathbf{1 4}, \mathbf{1 5}, \mathbf{1 6}$. Among such approaches, converting cellulose into a nano-sized material exhibits excellent properties like high surface area, high mechanical resistance, and stability that has been reported to show improved adsorption efficiency than the natural cellulose $[17,18,19]$.

45 In recent years, nanoscale inorganic metal oxides and hydroxides have shown significant outcomes in the removal of As and other groundwater

57 The present study is oriented towards developing an effective and environmentally benign solution using nanocellulose based iron-oxide inorganic nanomaterials onto the cellulose matrix with improved functions. Such chemically modified nanocelluloses have shown significant potential in the remediation of heavy metals, such as cadmium, lead, arsenic, and even radioactive pollutants like uranium [21, 22, 23, 24]. For instance, Wei et al. 2019 have reported the preparation of magnetic hybrid aerogel by integrating nanocellulose and ferroferric oxide $\left(\mathrm{Fe}_{3} \mathrm{O}_{4}\right)$ nanoparticles for effective removal of chromium $(\mathrm{Cr})(\mathrm{VI})$ ions. This hybrid aerogel also exhibits similar adsorption behavior on lead (Pb)(II) and copper $(\mathrm{Cu})(\mathrm{II})$ ions suggesting extended hybrid aerogel applications for removing heavy metal ions [25]. Likewise, Zarei et al. 2018 reported the synthesis of $\mathrm{Fe}_{3} \mathrm{O}_{4}$-nanocellulose compounds by acid hydrolysis and co-precipitation as well as sol-gel methods for the removal of mercury from wastewaters in the coastal cities of the Persian Gulf [26]. In another study, Taleb et al. 2016 reported the performance of two nanocellulose based adsorbents: (i) nanocellulose (NC) modified by PEG-6-arm amino polyethylene glycol, $\mathrm{PEG}-\mathrm{NH}_{2}$ (NC-PEG) for $\mathrm{Cd}^{2+}$ and $\mathrm{Ni}^{2+}$ removal and (ii) NC-PEG subsequently modified by precipitation iron oxide (FO) from goethite (NC-PEG/FO) has been found applicable for As(V) and As(III) removal [27] nanoparticles for arsenic remediation from arsenic contaminated groundwater. Although various nanocomposites containing nanocellulose and iron-oxide nanoparticles had been developed earlier [25, 26, 27], the bottleneck lies in their synthesis procedures that involve the use of toxic chlorine-based compounds as bleaching agents during nanocellulose extraction which are established as potent pollutants and carcinogens. Besides, the acid concentration for the isolation processes range $\sim 64 \%\left({ }^{W} / w\right) \mathrm{H}_{2} \mathrm{SO}_{4}$, and is often criticized for the environmental damage it causes and the incremental costs involved. Therefore, the necessity for developing a simple and appropriate method for synthesis of effective nanosorbents retaining high adsorption capacities and field applicability still exists. In the current study, we have reported two magnetically recoverable adsorbent systems for the sorptive removal of total dissolved As. The synthesis process involves the extraction of the nanocelluloses from agrowastes via total-chlorine free bleaching along with low concentrated acid hydrolysis step followed by single-step incorporation of iron oxide nanoparticles into the nanocellulose polymer matrix that makes the process more economical and environment-friendly. The adsorbent derived from rice husk bioresource is termed as Rice Husk-Nanocellulose Iron Oxide Nanobiocomposites (RH-NIONs) and the sugarcane bagasse derived adsorbent is 
parameters ( $\mathrm{pH}$ adsorbent dosage, total arsenic concentration, and contact time) on the adsorption of As, an empirical tool named Response surface methodology (RSM) was employed. The findings of RSM were then confirmed using Artificial Neural Networks (ANN) as a modeling tool and

the optimal conditions for total arsenic adsorption by the NIONs were derived. The adsorption process was further analyzed through isotherm and kinetic modeling and a comparative assessment of the adsorbents with other metals and field samples was carried. Comparative performance with respect to commercially available adsorbents has also been studied.

\section{Materials and methods}

\subsection{Materials and chemicals}

Rice husk (RH) and Sugarcane bagasse (SB) were collected as process wastes from local rice mills and jaggery production units, located in the district of Sonitpur, Assam, India. Sulfuric acid $\left(\mathrm{H}_{2} \mathrm{SO}_{4}\right)$, Sodium hydroxide $(\mathrm{NaOH})$, Hydrogen peroxide $\left(\mathrm{H}_{2} \mathrm{O}_{2}\right)$, ferrous sulfate heptahydrate ( $\left.\mathrm{FeSO}_{4} .7 \mathrm{H}_{2} \mathrm{O}\right)$, sodium citrate $\left(\mathrm{Na}_{3} \mathrm{C}_{6} \mathrm{H}_{5} \mathrm{O}_{7}\right)$, and urea $\left(\mathrm{NH}_{2} \mathrm{CONH}_{2}\right)$ of analytical grade were purchased from Merck India Pvt. Ltd. and used without further purification for the synthesis of the NIONs.

\subsection{Isolation of nanocelluloses from RH and SB}

81 The isolation of nanocellulose from RH and SB was carried out based on our previous experiences, [28] with appropriate modifications. The SB 82 and RH agro-waste precursors were milled separately in an SS316 stainless steel grinding container (50 ml) and processed in a planetary ball mill (EGOMA, India) at a frequency of $8.33 \mathrm{~Hz}$ until finely milled powders were obtained. The finely milled SB and RH powders (5g) were then 84 subjected to chemical processing by soaking in $\mathrm{NaOH}(3 \%$, w/w) solution which was successively autoclaved in an SS-316 Mechomine Teflon lined-autoclave (India) under $137895 \mathrm{~Pa}(20 \mathrm{Psi})$ at a temperature of $210 \pm 5^{\circ} \mathrm{C}$, for a period of $45 \mathrm{~min}$. Afterward, chlorine-free bleaching treatment was performed to the steam-exploded samples with a solution containing a predetermined amount of $\mathrm{H}_{2} \mathrm{O}_{2}$ and $\mathrm{NaOH}$. The as-obtained cellulose

87 was isolated from RH and $\mathrm{SB}$ were then acidified with $5 \% \mathrm{H}_{2} \mathrm{SO}_{4}$ and sonicated for $2 \mathrm{~h}$ at room temperature in a Labsonic $\mathrm{M}$ Ultrasonic

88 Homogenizer from Sartorius (Germany) to obtain the nanocelluloses.

\subsection{Synthesis of RH-NIONs and SB-NIONs}

90 The nanocelluloses obtained from RH and SB (5g) were added separately into a solution of ferrous sulfate heptahydrate $(0.3 \mathrm{~mol})$, urea (1 mol), 91 and sodium citrate $(0.1 \mathrm{~mol})$ and subjected to solvothermal treatment for five different time intervals viz. $1 \mathrm{~h}, 2 \mathrm{~h}, 3 \mathrm{~h}, 4 \mathrm{~h}$, and $5 \mathrm{~h}$. The synthesized 92 RH-NIONs and SB-NIONs were separated from the solution by a magnet and rinsed with deionized water three times, followed by absolute alcohol 93 and acetone. The NIONs were finally vacuum dried at $\sim 40{ }^{\circ} \mathrm{C}$ for a period of $\sim 12 \mathrm{~h}$ prior to further investigations. A schematic representation of 94 their synthesis and subsequent optimization using chemometric tools is shown in Fig. 1. 


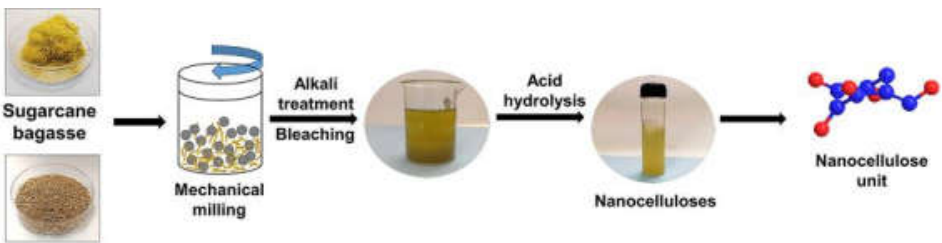

Rice husk
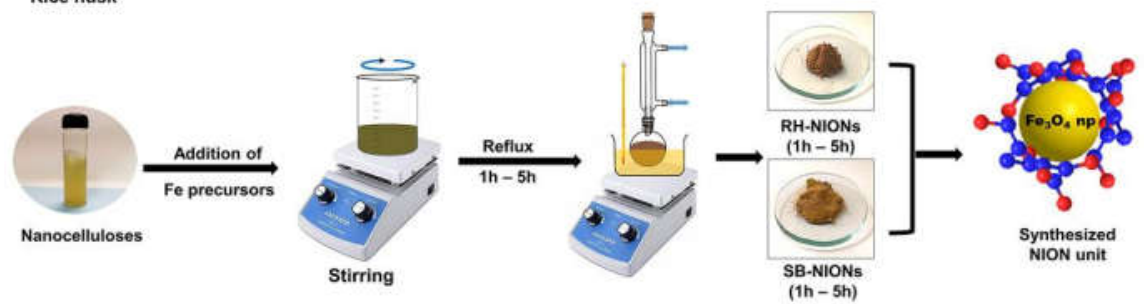

Solvothermal synthesis of SB and RH-NION variants

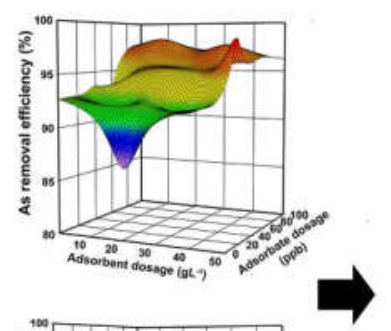

SB-NION

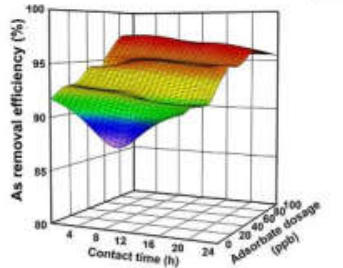

RH-NION

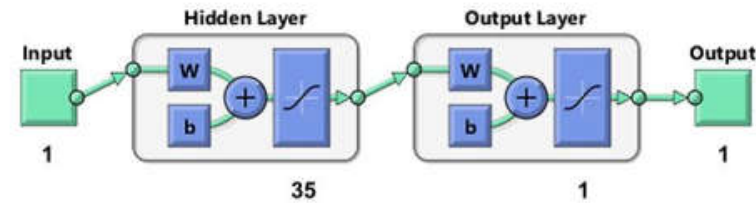

Influence of parametric interactions on As adsorption using RSM and ANN

96 Fig. 1. Schematic representation of the synthesis and optimization of SB and RH-NIONs for the removal of As.

\section{2.4. Experimental design}

\subsubsection{RSM Modeling}

Response surface methodology (RSM) is defined as a statistical tool that simultaneously optimizes levels of independent variables to achieve the best system performance [29]. RSM was employed to study the influence of univariate and multi-variate interactions between the adsorption parameters on As removal efficiency and determine the optimal conditions. In this context, adsorbate dosage, adsorbent dosage, $\mathrm{pH}$, and contact time were chosen as the variables of concern. Central Composite Design (CCD) was adopted to produce a minimum number of variations for the aforementioned four factors [30]. A total of 30 experiments were designed for the quadratic model and artificial neural network study, involving four factors at five levels (Table S6). The adsorption data were modeled using the following second-order polynomial function to express the correlation between the predictive response and the experimental factors [31]:

$$
\mathbf{Y}=\mathbf{b}_{\mathbf{0}}+\sum_{\mathrm{i}=1}^{\mathrm{n}} \mathbf{b}_{\mathbf{i}} \mathbf{X}_{\mathbf{i}}+\sum_{\mathrm{i}=1}^{\mathbf{n}} \mathbf{b}_{\mathrm{ii}} \mathbf{X}_{\mathbf{i}}^{2}+\sum_{\mathrm{i}=\mathbf{1}}^{\mathbf{n}} \sum_{\mathrm{i}>\mathbf{j}}^{\mathrm{n}} \mathbf{b}_{\mathrm{ij}} \mathbf{X}_{\mathrm{i}} \mathbf{X}_{\mathbf{j}}
$$


Where $\mathrm{Y}$ is the predictive response, $\mathrm{b}_{0}$ is the model constant, $\mathrm{b}_{\mathrm{i}}$ is the linear coefficient, $\mathrm{b}_{\mathrm{ii}}$ is the interaction coefficients, $\mathrm{b}_{\mathrm{ij}}$ is the quadratic coefficient, and $X_{i}$ and $X_{j}$ are the coded values and $n$ is the total number of variables.

In this study, the Design-Expert 7.0 statistical software package (Stat-Ease Inc. USA) was used for the regression analysis, graphical analysis, and analysis of variation (ANOVA).

\subsubsection{ANN Modelling}

ANN is a parallel distribution processing system composed of neurons and weights and is based on the principle of a highly interconnected system of simple processing elements capable of learning complex interrelations between dependent and independent variables. The network contains an input layer, a hidden layer, and an output layer (Fig.1). The most popular ANN is Multilayer Perception (MLP) based ANN which consists of comparing responses of output units to desired responses through an iterative process where an error term is calculated to readjust the weights in the network so that the network responses are obtained close to the desired responses. In this study, the findings from the RSM studies were validated with MLP based ANN study using the MATLAB R2013a computing suite (MathWorks USA) [32, 33]. The performance of RSM and ANN models was compared using several statistical parameters viz. coefficient of determination ( $\left.\mathrm{R}^{2}\right)$, mean squared error (MSE), root mean square error (RMSE), mean absolute deviation (MAD) and mean absolute percent error (MAPE) (Table S2).

\subsection{Adsorption isotherms and kinetics}

The adsorption capacity was determined against standard curves of total As using an Atomic Emission Spectrophotometer (Agilent 4200 Microwave Plasma-Atomic Emission Spectrophotometer, USA). The adsorption of As by the NIONs was modeled using pseudo-first-order (PFO) and pseudosecond-order (PSO) kinetic equations (Table S3) using the OriginPro $8^{\circledR}$ graphing suite. Further, to gain an insight into the underlying mechanism of As removal by the NIONs, the quantitative adsorption of As by the optimal SB and RH-NION solvothermal variants were measured as a function of non-linear Langmuir, Freundlich, and Sips isotherm equations [34]. In addition, the adsorption capacity of the NIONs was determined using the equation $[35,36]$ :

$$
\mathbf{q}_{\mathbf{e}}=\frac{\left(\mathbf{C}_{0}-\mathbf{C}_{\mathbf{e}}\right) \mathbf{V}}{\mathbf{M}}
$$

Where, $\mathrm{q}_{\mathrm{e}}$ is the equilibrium adsorption $\left(\mathrm{mgg}^{-1}\right) \mathrm{C}_{0}$ and $\mathrm{C}_{\mathrm{e}}$ are the initial and equilibrium As concentration in solution (ppb), respectively. V and $\mathrm{M}$ are the volumes of studied solution $(\mathrm{ml})$ and the mass of NIONs for each solution $(\mathrm{mg})$, respectively.

\subsection{Analysis and characterization}

The morphology and particle size of the synthesized NIONs were studied using Transmission Electron Microscopy (TEM) (JEOL JEM-2100, Japan) and their average dimensions were determined using the Image J (NIH) processing suite. The magnetic properties of the NIONs were characterized using a Dynacool Model-9 physical property measurement system (PPMS, Quantum Design, USA). An X-ray powder diffractometer (RIGAKU-Miniflex Benchtop, Japan) was used to analyze the crystalline structures of the adsorbents. Fourier-transform Infrared (FTIR) spectra of the two adsorbents before and after adsorption were recorded on a Perkin Elmer-Spectrum 100 Optica FT-IR Spectrometer, USA. To determine the amount of iron oxide impregnated within these nanocellulosic matrices, the adsorbents were digested in the presence of a strong acidic medium 
and the Fe (\%) content was estimated using Atomic Emission Spectroscopy (Agilent Technologies-Agilent 4200 MP-AES, USA) against standard curves of Fe. The molecular weight of cellulose and the degree of polymerization (DOP) of cellulose within the nanocellulosic NION matrices was estimated using Photon Correlation Spectroscopy (Malvern P analytical-Zetasizer Nano ZS-90, UK). To detect the binding energies and atomic ratio of adsorbents surface, X-ray photoelectron spectroscopic (XPS, Thermo Fisher Scientific Pvt. Ltd., ESCALAB Xi+, UK) analysis was carried out.

\section{3. Results and discussion}

\section{3.1. Characterization of the NIONs}

144 The TEM analysis provided insights on the topological features of the SB and RH-NIONs (Fig. 2a-f). At low magnifications, the SB and RH-

NIONs show the presence of an irregular matrix suggesting the presence of nanocellulose fibers (Fig. 2a, d). This is attributed to the fibrillation of the milled SB and RH during the high-temperature solvothermal synthesis of NIONs [37]. At higher magnifications, the growth of quasi-spherical iron oxide nanoparticles within these fibrillated SB and RH nanocellulose matrices is clearly observed in both the NIONs (Fig. 2b, e). As estimated from the TEM micrographs, the average radius of these iron oxide nanoparticles was found to be $\sim 4.8 \mathrm{~nm}$ for the SB-NIONs and $\sim 7.6 \mathrm{~nm}$ for the RH-NIONs respectively. The iron oxide particles also show the presence of lattice fringes, which suggests the crystalline nanostructure of $\mathrm{Fe}_{3} \mathrm{O}_{4}$ (Fig. 2b inset, e inset). This is further reflected in the SAED patterns of the NIONs (Fig. 2c, f), which show the characteristic diffraction signatures for $\mathrm{Fe}_{3} \mathrm{O}_{4}$, corresponding to the 220, 311, and 440 diffraction planes. This is also indicative of the inverse spinel $\mathrm{Fe}_{3} \mathrm{O}_{4}$ phase [38]. The XRD analysis confirms the presence of inverse spinel cubic-phase $\mathrm{Fe}_{3} \mathrm{O}_{4}$ in both the NIONs. All the XRD spectra of SB and RH-NIONs (Fig. $\mathbf{2 g}, \mathbf{h})$ display three well-defined peaks at $2 \theta=23^{\circ}, 30^{\circ}$ and $35^{\circ}$ which corresponds to the crystal planes (002) for crystalline nanocellulose and (220) and (311) for inverse spinel cubic-phase $\mathrm{Fe}_{3} \mathrm{O}_{4}$ (JCPDS No: 19-6029) [38, 39, 40]. A minor peak at $2 \theta=65^{\circ}$ was also observed in the XRD spectra of the SB-NIONs, which is attributed to the 440 diffraction plane of cubic phase $\mathrm{Fe}_{3} \mathrm{O}_{4}$ [40]. Furthermore, characteristic infrared signatures relating to nanocelluloses and $\mathrm{Fe}_{3} \mathrm{O}_{4}$ bound nanocelluloses were also observed in the FT-IR spectra of the SB and RH-NIONs which are discussed in detail in Section 3.5 .

The percentage Fe composition in the SB and RH-NIONs was determined to recognize a possible correlation between the progressive increase in solvothermal residence time and the impregnation of the $\mathrm{Fe}_{3} \mathrm{O}_{4}$ nanoparticles into the $\mathrm{SB}$ and $\mathrm{RH}$ nanocellulosic matrices. The spectroscopic measurements of the NION variants reveal a progressive increase in the Fe content from an initial $23 \%$ for the $1 \mathrm{~h}$ SB and RH-NION up to $57 \%$ and $41 \%$ for the $5 \mathrm{~h} \mathrm{SB-NION}$ and $5 \mathrm{~h}$ RH-NION respectively (Fig. $2 \mathrm{~g}$ inset, $\mathbf{h}$ inset). Thus, the degree of $\mathrm{Fe}_{3} \mathrm{O}_{4}$ impregnation in the nanocellulosic matrix progressively increased, as the solvothermal residence of the NIONs increased from $1 \mathrm{~h}$ to $5 \mathrm{~h}$. Further, estimations of the cellulosic degree of polymerization of SB and RH-NIONs were carried out based on their molecular weight and found to be $1900 \pm 20 \mathrm{DP}$ and $1650 \pm 25 \mathrm{DP}$ respectively. This high cellulosic degree of polymerization suggests that the SB and RH-NIONs matrices are rich in long-chain nanocellulosic structures consisting of numerous surface hydroxyl $(-\mathrm{OH})$ groups. The availability of these surface $-\mathrm{OH}$ groups is likely to enhance the As remediation properties of the NIONs because of their affinity towards dissolved As [41]. This also confirms the high structural stability of the NIONs under various solvent conditions.

The presence of magnetic characteristics of the synthesized SB and RH-NIONs was measured using a physical property measurement system (PPMS). The results showed that the remnant magnetization and coercive field values of specific magnetization curves for both the NIONs were negligible which confirms their superparamagnetic nature [42]. The magnetization curve of the SB-NION saturated at $\sim 0.5$ emug ${ }^{-1}$ while that of the 
RH-NION saturated at $\sim 1$ emug $^{-1}$ (Fig. 2i, j). The superparamagnetic character is a valuable attribute for facilitating the magnetic recovery of 172 NIONs from water samples to enable its recyclability and reuse. To experimentally validate this attribute, the superparamagnetic SB and RH173 NIONs were recovered under the influence of an external magnetic field. It was observed that the well-dispersed SB and RH-NIONs (Fig. 2i inset,
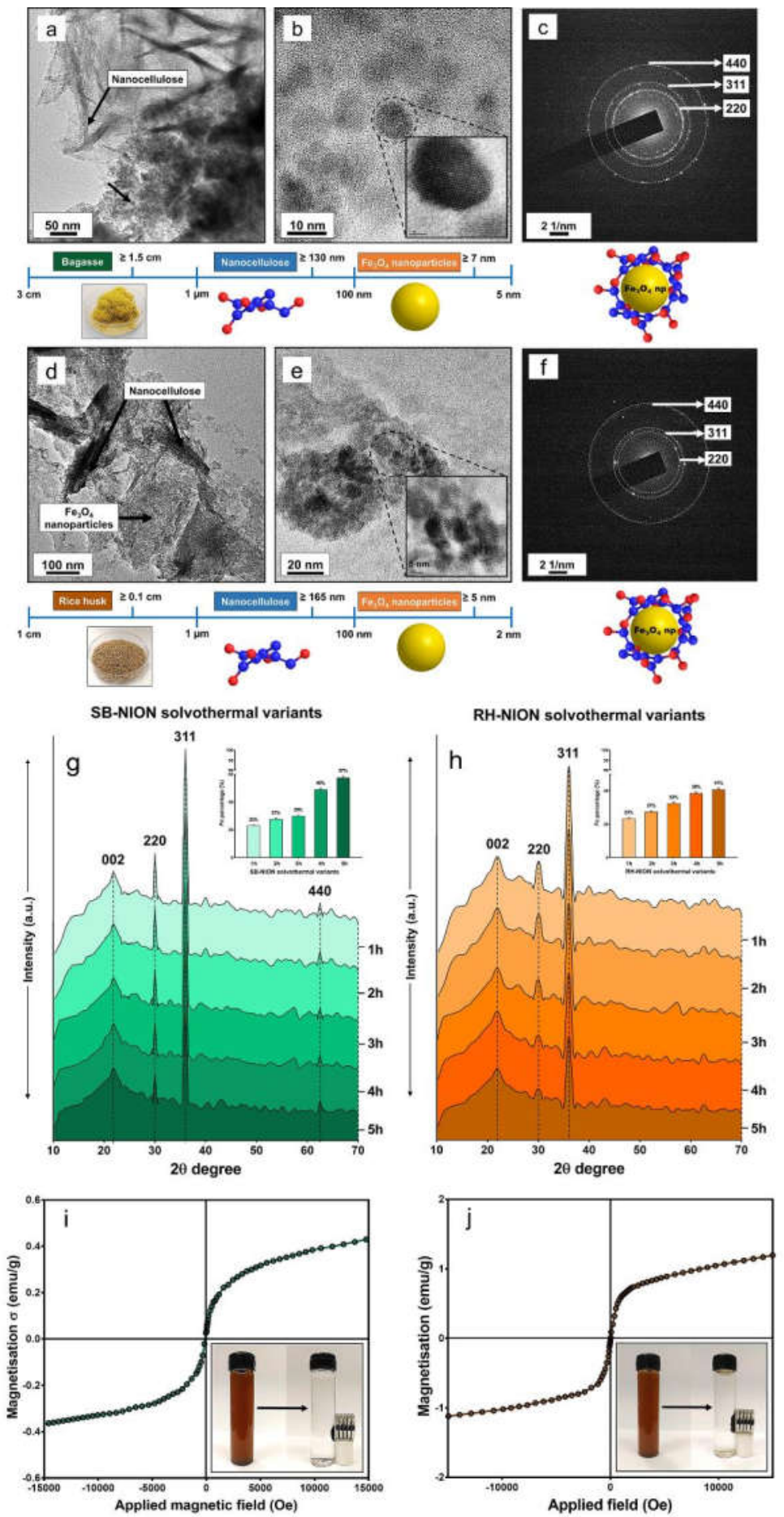
Fig. 2. TEM micrographs of the SB-NION $(a, b)$ and $\mathrm{RH}-\mathrm{NION}(\mathrm{d}, \mathrm{e})$ with scale diagrams of precursor materials, derived nanocellulose and $\mathrm{Fe}_{3} \mathrm{O}_{4}$ NPs, selected area electron diffraction (SAED) patterns of the SB-NION (c) and RH-NION (f); comparative X-ray diffractograms of the synthesized SB-NION solvothermal variants (g) and the RH-NION solvothermal variants (h); Fe content (\%) of the synthesized SB-NIONs (g inset) and RHNIONs (h inset); magnetic hysteresis (M-H) curve for the synthesized SB-NION (i) and RH-NION (j) and magnetic recovery of SB-NION (i inset) and RH-NION ( $\mathrm{j}$ inset) in As solution under the influence of external magnetic field (214 Gauss).

\subsection{Modelling and optimization using RSM}

In our study, the experimental parameters considered were adsorbate dosage, adsorbent dosage, $\mathrm{pH}$ and contact time within defined boundary levels with $95 \%$ confidence limit (Table S1). Thus, a five level-four factor $\left(5^{4}\right)$ full factorial CCD, leading to a total of 30 experimental runs was employed for optimization of SB-NION and RH-NION. The results obtained for each combination are given in Table S6. The empirical relations between the four variables and the removal efficiency of As by the two adsorbents are described by the equations as follows:

As removal efficiency of RH-NION (\%) $=+101.54093-0.90081 \times \mathrm{A}+0.12301 \times \mathrm{B}+0.33039 \times \mathrm{C}-0.27567 \times \mathrm{D}+0.021798 \times \mathrm{A} \times \mathrm{B}+0.041568$ x A x D -0.028235 x B x C -0.018187 x B x D -0.071884 x C x D + 0.010394 x A ${ }^{2}-0.011267 \times B^{2}+0.036321 \times C^{2}-7.93116 E-003 \times D+$ $2.52070 \mathrm{E}-003 \times \mathrm{B} \times \mathrm{C} \times \mathrm{D}-3.02532 \mathrm{E}-004 \times \mathrm{A}^{2} \times \mathrm{B}-3.76187 \mathrm{E}-004 \times \mathrm{A}^{2} \times \mathrm{D}+1.95595 \mathrm{E}-004 \times \mathrm{A} \times \mathrm{B}^{2}$

As removal efficiency of SB-NION $(\%)=+79.95382+0.50252$ x A +0.084804 x B -0.34624 x C -0.20229 x D $-2.88335 \mathrm{E}-004$ x A x B 4.02971E-003 x A x C + 1.52974E-003 x A x D + 3.81898E-003 x B x C - 1.03299E-003 x B x D - 3.49242E-003 x C x D - 3.19711E-003 x A² 6.15267E-004 $\times \mathrm{B}^{2}+0.038551 \times \mathrm{C}^{2}+5.91028 \mathrm{E}-003 \times \mathrm{D}^{2}$

Where, $\mathrm{A}=$ Adsorbate dosage $(\mathrm{ppb}), \mathrm{B}=$ Adsorbent dosage $\left(\mathrm{gL}^{-1}\right), \mathrm{C}=$ Solvent $\mathrm{pH}$ and $\mathrm{D}=$ contact time (h) with the adsorbent.

The predicted results showed good agreement with the experimental data. Analysis of the variance (ANOVA) was used to assess the statistical significance, the adequacy of the fit, and the competency of the predicted models (Table S4). Variables with a p-value less than 0.05 have a significant effect on the response and show the accuracy of the model. However, for higher accuracy, the p-value for lack of fit should be higher than 0.05 . Table S4 shows that the lack of fit values for both SB and RH-NIONs are higher than 0.05 which confirms the accuracy of the predicted models. Table S4 also presents the value of $\mathrm{R}^{2}$ for both SB and RH-NIONs and were found to be 0.96 and 0.97 , which suggests that $96 \%$ and $97 \%$ of the total variations in the experimental parameters could be elucidated by the RSM predictive models. The Pareto plots illustrated in Fig. 3a, b explains the impact of the variables on the response. The Pareto chart for SB-NIONs (Fig. 3a) indicates that the influence of univariate deviations in the process parameters was found to be the most significant on the adsorption of As which also corroborates with results obtained from Table S4. On the other hand, for RH-NIONs the RSM investigations demonstrate univariate, bi-variate, and multi-variate interactions between the process parameters to have a significant influence on the adsorption of As. Thus, in comparison with the RH-NIONs, the SB-NIONs were found to be more resistant to changes in parametric variability, suggesting their better suitability as an effective adsorbent for dissolved As under various parametric conditions.

Fig. 3c and 3d demonstrate the response surface 3D plots for the effect of bi-variate interactions of RH-NIONs for As removal. As evident from the response surface plot (Fig.3c) the interactions between adsorbent dosage and adsorbate dosage was found to have a significant influence on the adsorption of As and a maximum As removal efficiency of $\sim 97 \%$ was observed with adsorbate dosage of $\sim 76$ ppb and an adsorbent dosage of $\sim 38$ $\mathrm{gL}^{-1}$. Interactions between adsorbate dosage and contact time were also found to be significant where a maximum As removal efficiency of $\sim 96 \%$ 
was observed, using a $\sim 76 \mathrm{ppb}$ adsorbate dosage for a contact time of $\sim 18 \mathrm{~h}$ (Fig. 3d). Furthermore, the RSM investigations for RH-NIONs also showed multi-variate interactions between adsorbent dosage, contact time and $\mathrm{pH}$ to have a significant influence on the adsorption of As (Fig. 3e). A maximum As removal efficiency of $99 \%$ was observed for this multi-variate interaction using an adsorbent dosage of $\sim 38 \mathrm{gL}^{-1}$ for a contact time of $\sim 18 \mathrm{~h}$ at $\mathrm{pH} \sim 10$.

\subsection{Modeling and optimization using ANN}

To validate the findings of RSM studies with MLP base AAN study the experimental data was divided into three portions for the purpose of training $(70 \%)$, testing $(15 \%)$, and validation $(15 \%)$ to keep the network away from overtraining and over parameterization [43]. The parameters adsorbate dosage, adsorbent dosage, $\mathrm{pH}$, and contact time were taken as input together at a time and the As removal efficiency was set as output values from the experimental results. The number of neurons in the input layer (4) was assigned based on the number of input parameters while the number of neurons in the output layer (1) was assigned based on the desired output. The network was optimized by varying the number of neurons in the hidden neuronal layer in the range 5-100 where a minimum of 10 training runs was carried out for each ANN topology [44]. The rigorous iteration was performed in each case to obtain an optimized combination of training. The performance indicators were selected as mean squared error (MSE) values and determination coefficients $\left(\mathrm{R}^{2}\right)$. The ANN topologies of 4-15-1 and 4-35-1 showed the lowest MSE values of 0.003 and 0.03 respectively and were used for the predictive modeling of
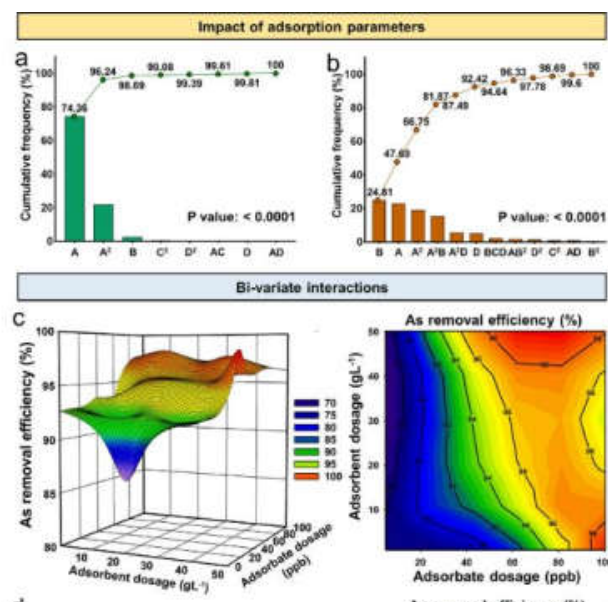
Fig. 3. Pareto chart showing the impact of various experimental parameters in the adsorption of As by the 5h SB-NION (a) and RH-NION (b); effect of bi-variate interactions on the adsorption of As by the 5h RH-NION (c, d); cubic plot showing the effect of multi-variate interactions on the adsorption of As by the $5 \mathrm{~h}$ RH-NION (e) as described by the CCD matrices of RSM.

As adsorption using SB and RH-NIONs (Fig. S2 a, b; Table S5). Various error functions were used to assess the accuracy of the model which are given in Table S2. The determination coefficients for both of the ANN topologies were found to be 0.99 , which suggests that $99 \%$ of the total variations in the experimental parameters could be elucidated by these ANN predictive models (Table S6).

\subsection{Comparison of the predictive chemometric models}

231 The predictive outputs of the RSM and ANN-based chemometric models of SB and RH-NIONs were compared to that of the experimental results and are depicted in Table S6. Their performance was evaluated based on the linear correlation plots and the distribution of residuals is shown in Fig. 4. The high $\mathrm{R}^{2}$ values $(>0.9)$ for the linear correlation plots suggest that both RSM and ANN chemometric models were in good agreement with that of the experimental results (Table S7, Fig. 5a). This confirms the suitability of both RSM and ANN predictive models for the optimization of As adsorption. In addition, the better $\mathrm{R}^{2}$ values of the ANN models (Fig. 4a) and the localization of their residual values, close towards the central line (Fig. 4b) suggest that the predictions of the ANN models were closer to the experimental values in comparison to the RSM models. This is further supported by the MSE, RMSE, MAD, and MAPE based statistical values measured for both RSM and ANN models, where the values are significantly better for ANN models in comparison to RSM (Table S6). The results thus confirm the superior nature of the ANN models over RSM for predictive optimization of experimental parameters and are consistent with similar studies carried out earlier. However, ANN-based models lack the ability to describe the impact of experimental parameters on the experimental output based on relative significance/insignificance using mathematical frameworks, which is a remarkable attribute of RSM-based predictive models [33]. Thus, in the current study, the combined use of RSM and ANN predictive models was found to be crucial in understanding the significant impact of the experimental parameters on the adsorption of As with improved approximation and generalization capabilities for predictive assessments.

\section{a}
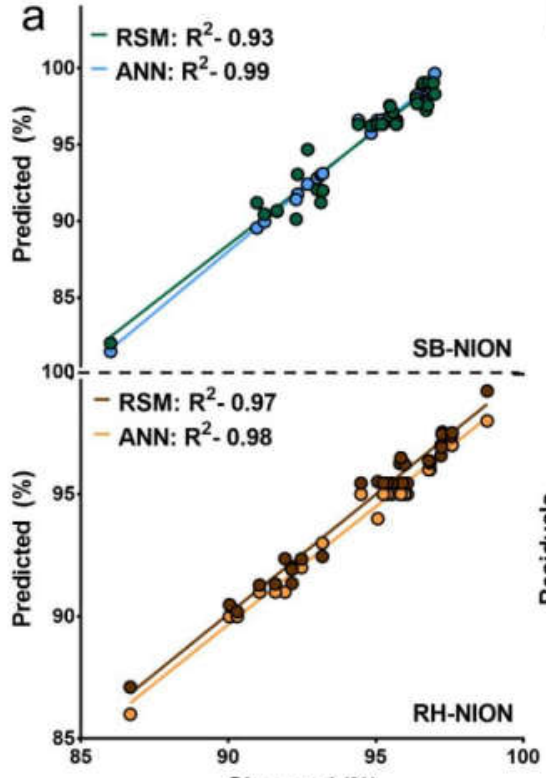

Observed (\%)

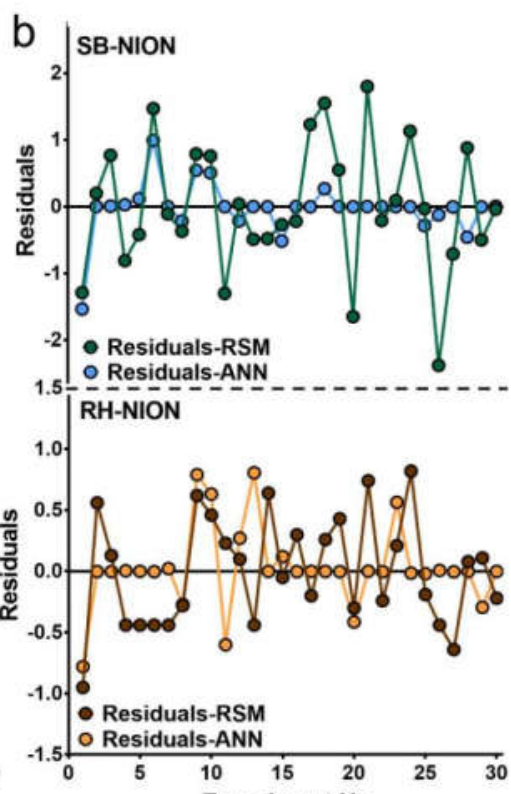

Experiment No. 
Fig. 4. Comparison of predictive outputs of RSM and ANN-based chemometric models based on determination coefficient (a) and distribution of residuals (b) for the adsorption of As by the 5h SB-NION and 5h RH-NION.

\subsection{Study of adsorption isotherms, adsorption kinetics, and mechanism of adsorption}

The rate-limiting step behind the adsorption of As by NIONs under the optimal parametric conditions was determined by the adsorption equilibrium data. The adsorption equilibrium data were fitted using linear forms of two conventional kinetic models viz. Lagergren's pseudo-first-order model and Ho's pseudo-second-order model (Fig. 5a, b). Based on the $\mathrm{R}^{2}$ values and $\chi^{2}$ measures of precision, the pseudo-second-order plots from Fig.

$\mathbf{5 b}$ indicates that the adsorption of As by the SB and RH-NIONs follow pseudo-second-order kinetics. This is further confirmed from the calculated adsorption capacities ( $\mathrm{q}_{\mathrm{e}}$ calc) of the pseudo-second-order plots for the NIONs, which were in good agreement with that of the experimental ( $\left.\mathrm{q}_{\mathrm{e}}\right)$ adsorption capacities (Table $\mathbf{S 7}$ ). The rate-limiting step for the adsorptive process governed by pseudo-second-order kinetics has primarily been attributed to a chemisorptive mechanism involving covalent binding and/or ionic interactions between the adsorbent and the adsorbate $[45, \mathbf{4 6}$.

Langmuir, Freundlich, and Sips isotherms were also used to investigate the adsorption of As by SB and RH-NIONs under the optimal experimental conditions. The Sips adsorption isotherm describes best the As adsorption processes for both SB and RH- NIONs which is further confirmed by the $\mathrm{R}^{2}$ values (0.97-0.94) together with the derived MAD, MSE, RMSE and MAPE values (Fig. 5c, Fig. S3). The Sips heterogeneity factor $\left(\mathrm{n}_{\mathrm{s}}\right)$ which denotes the nature of the adsorption process, was derived from the non-linear plots and was found to be 1.9 and 1.8 for SB and RH-NIONs respectively (Fig. 5c, Fig. S3). This along with the findings of the kinetics studies suggests the adsorption of As to be mediated through covalent interactions between the NIONs and the dissolved As. Therefore, the findings confirm chemisorption to be a dominant mechanism governing the adsorption of dissolved As by the NIONs [46]. The maximum As adsorption capacities of the NIONs were also derived from the fitted isotherms and found to be $>550 \mathrm{mgg}^{-1}$ for SB-NIONs which was observed to be appreciably better than that of RH-NIONs $\left(\sim 100 \mathrm{mgg}^{-1}\right)$ under optimal adsorption conditions.
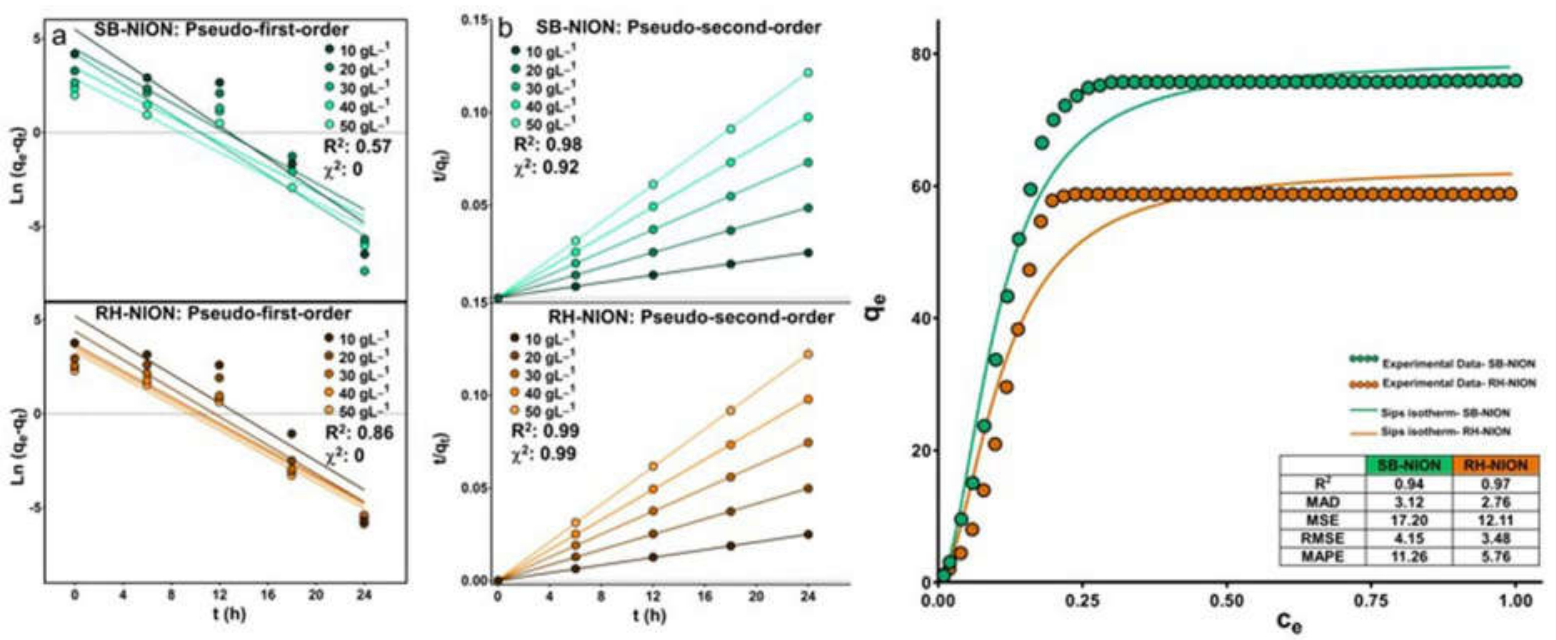

Fig. 5. Pseudo-first-order (a), pseudo-second-order (b) adsorption kinetics curves, and non-linear fits of Sips adsorption isotherm plot for the adsorption of As by the SB-NION and the RH-NION (c). 
To further gain insight into the mechanistic interaction between the dissolved As and the active sorption sites in the adsorbents, the SB-NION was assessed using X-ray photoelectron spectroscopy (XPS) and Fourier transform infrared spectroscopy (FT-IR), both prior to and after As adsorption under optimal conditions. The FT-IR spectroscopic studies of both SB-nanocellulose and SB-NION composite shows the presence of several bonds formed by oxygen functional groups. These include a broad absorption band at $3415 \mathrm{~cm}^{-1}$ region (Fig. 6a) corresponding to the O-H stretching vibration modes for nanocelluloses. The band at $2903 \mathrm{~cm}^{-1}$ can be attributed to the aliphatic C-H stretching vibration modes of nanocellulose and those bands at $1654 \mathrm{~cm}^{-1}$ and $1115 \mathrm{~cm}^{-1}$ may be attributed to $\mathrm{O}-\mathrm{H}$ bending and $\mathrm{C}-\mathrm{O}$ stretching vibrations of nanocellulose [47, 39]. The peaks at 611 $\mathrm{cm}^{-1}$ and $422 \mathrm{~cm}^{-1}$ in the spectrum of SB-NION prior to As adsorption corresponds to C-O stretching vibration and Fe-O bending vibration indicating that $\mathrm{Fe}_{3} \mathrm{O}_{4}$ nanoparticles were successfully attached to the nanocellulose surfaces. The spectrum of SB-NION after As adsorption shows that the bands at $3415,2903,1654$, and $1115 \mathrm{~cm}^{-1}$ have decreased in the intensity which is the outcome of the complexation of the oxygen functional groups with As (III) ions. In addition, the oxygen atoms present in hydroxyl groups possess free pair of electrons that are likely to interact with the empty orbital of As (III) and form complexes through coordinative bonds [41, 48]. On the other hand, the decreased in intensity of the peaks at 611 and $422 \mathrm{~cm}^{-1}$ is indicative of the prominent interaction of $\mathrm{C}-\mathrm{O}$ and $\mathrm{Fe}-\mathrm{O}$ bonds with As through bidentate binuclear corner-sharing (2C) complexes between As(III)

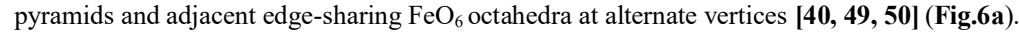
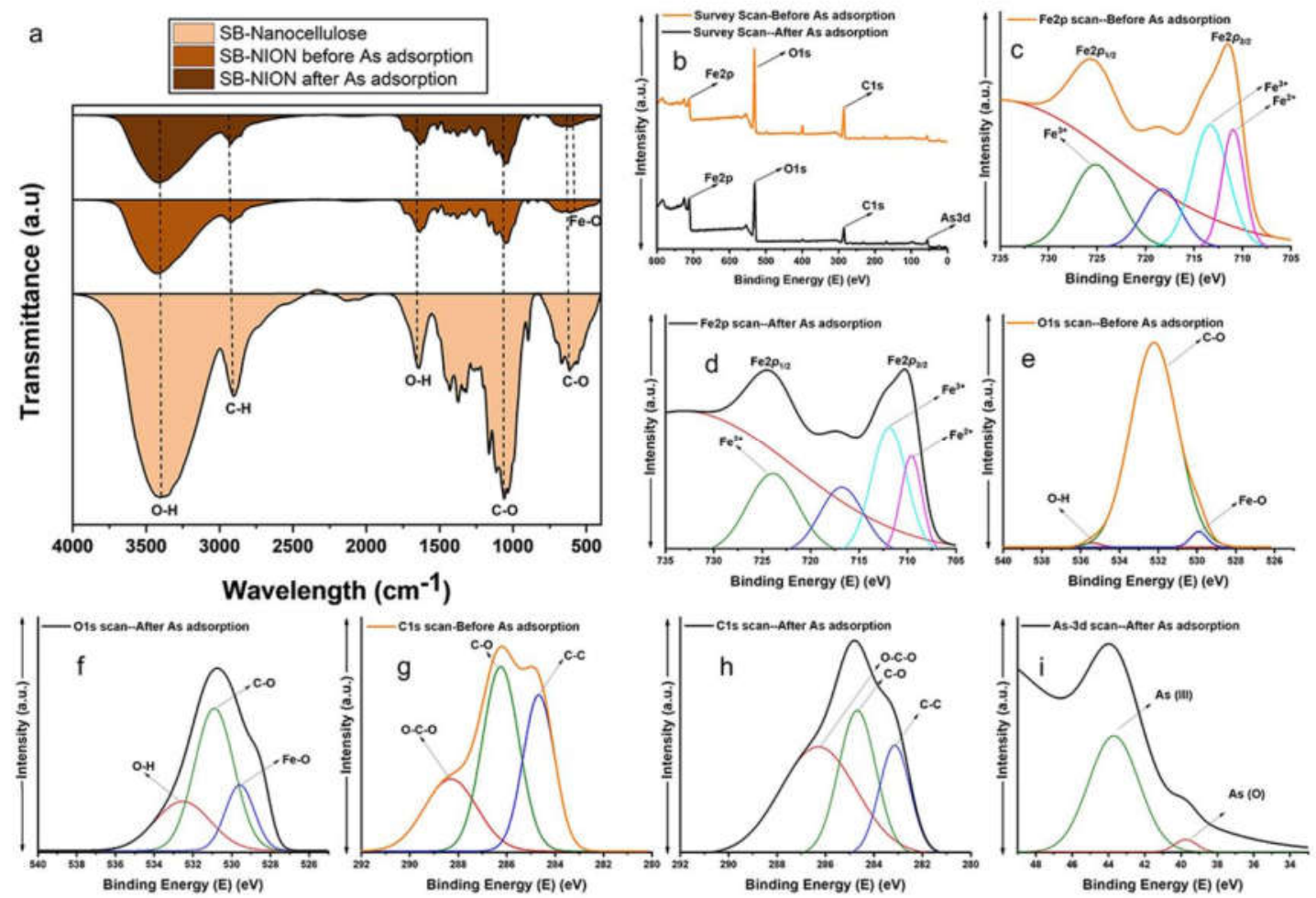

Fig. 6. Comparative FTIR spectra of the SB- nanocellulose, SB-NION before adsorption and SB-NION after adsorption (a); XPS-survey scan of the SB-NION before and after As adsorption (b); Fe (2p) XPS spectra (c, d); O (1s) XPS spectra (e, f); C (1s) XPS spectra (g, h); before and after As adsorption and As (3d) XPS spectra (i) after the adsorption of As by the SB-NION. 
The wide-scan survey XPS spectra of SB-NION (Fig. 6b), show prominent photoelectron lines at binding energies of $711.3 \mathrm{eV}, 530.5 \mathrm{eV}$, and 284.0 $\mathrm{eV}$ both before and after the adsorption of As that may be attributed to $\mathrm{Fe}(2 p), \mathrm{O}(1 s)$ and $\mathrm{C}(1 s)$ respectively. Additionally, an apparent As (III) peak at a binding energy of $44.5 \mathrm{eV}$ is observed in the post-adsorption wide-scan survey spectrum thus indicating that the adsorbent has taken up As (III) efficiently. High-resolution XPS scans for the Fe (2p) photoelectron signature (Fig. 6c) further shows the presence of Fe2p $1 / 2$ and Fe $2 p^{3 / 2}$ photoelectron peaks, which upon de-convolution revealed individual peaks at $725.0 \mathrm{eV}(\mathrm{Fe} 3+), 711.5 \mathrm{eV}\left(\mathrm{Fe}^{3+}\right)$ and $710.5 \mathrm{eV}\left(\mathrm{Fe}^{2+}\right)$, characteristic of mixed-phase $\mathrm{Fe}_{3} \mathrm{O}_{4}$ nanoparticles [51]. These $\mathrm{Fe}(2 \mathrm{p})$ signatures appear to shift towards lower binding intensities (Fig. 6d), which suggests covalent bonding between $\mathrm{Fe}_{3} \mathrm{O}_{4}$ and As though multi-dentate nuclear complexes [52]. The $\mathrm{O}$ 1s peaks appear to consists of three components at $533 \mathrm{eV}, 531 \mathrm{eV}$, and $530 \mathrm{eV}$ (Fig. 6e, f) that suggest the presence of oxygen functional groups; O-H, C-O, and Fe-O respectively, which is consistent with the IR spectra. Further, the $\mathrm{C} 1 \mathrm{~s}$ peak fits of $\mathrm{O}-\mathrm{C}-\mathrm{O}(288 \mathrm{eV}), \mathrm{C}-\mathrm{O}(286 \mathrm{eV})$, and $\mathrm{C}-\mathrm{C}(284 \mathrm{eV})$ also attribute to the presence of oxygen functional groups that undergo a prominent decrease in intensities after adsorption (Fig. 6g). These decrease in intensities are likely to occur due to the complexation of oxygen functional groups of SB-NION with As (III) which was further revealed by the dominance of As (III) peak at a binding energy of $44 \mathrm{eV}$ (Fig. $\mathbf{6 h}$ ). The findings are also in agreement with the trends observed in the FTIR spectroscopic studies, which suggests that the underlying mechanism of As adsorption may be attributed to the formation of nanocellulose: $\mathrm{As}$ and $\mathrm{Fe}_{3} \mathrm{O}_{4}$ : As multidentate covalent complexes, during the adsorption of As by the adsorbents as shown in Fig. 7.

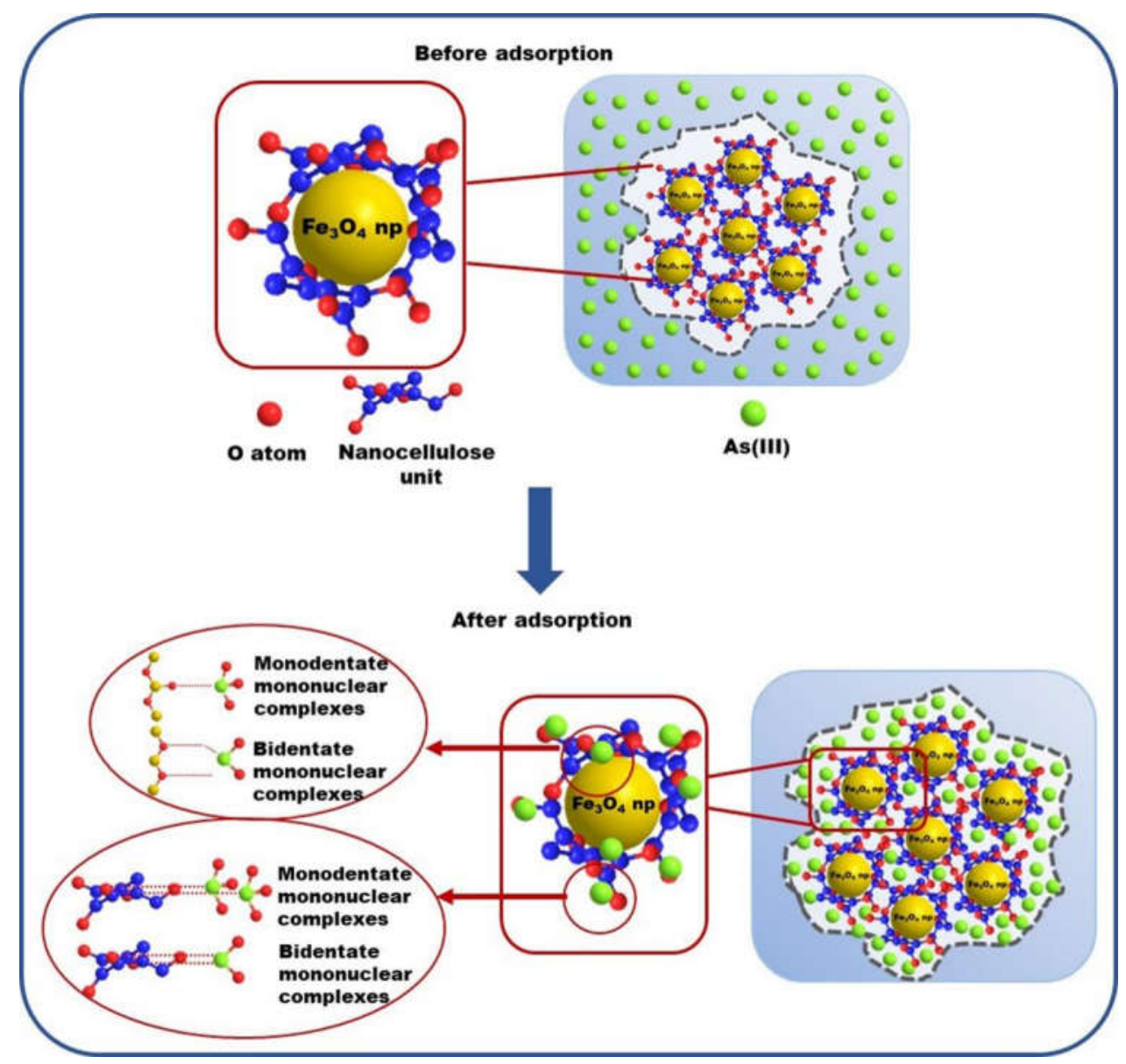


3.6. Assessment of NION performances with contaminated groundwater samples (other heavy metals), recyclability, and

The recyclability performance of an adsorbent is a key concern in terms of cost-effectivity and applicability for an actual water treatment system.

Hence, the recyclability assessments for both SB and RH-NIONs were performed under the optimal conditions derived from RSM and ANN-based chemometric investigations. Desorption experiment was conducted to examine the reusability of the adsorbents. Desorption may occur either by thermal treatment or through suitable desorbing agents like acid or alkali solutions. In the present study, however, a chemic al method of regeneration was employed in a neutral solution. The arsenic-loaded adsorbents obtained after the adsorption process was added into a $50 \mathrm{ml}$ of Phosphate Buffer Saline (PBS) solution ( $\mathrm{pH} 7.4$ ) as the desorbing agent. The solution was shaken at $150 \mathrm{rpm}$ and then agitated at specific time intervals for up to 24 h. The solution was then centrifuged and the desorbed NIONs were re-incubated in $100 \mathrm{~mL}$ of $100 \mathrm{mgL}^{-1}$ As solutions. Adsorption-desorption experiments were repeated up to 5 successive cycles under the optimum condition to determine their reusability. Fig. 8a demonstrates that the SBNIONs have shown better results compared to RH-NIONs retaining an appreciable As removal efficiency of $\sim 79 \%$ at the end of five successive cycles. The adsorption capacity of the individual components viz. native, milled SB and RH powders, SB and RH derived nanocelluloses, and the native magnetic $\mathrm{Fe}_{3} \mathrm{O}_{4}$ nanoparticles formed during NION synthesis were also evaluated (Table S8). The native SB and RH precursors showed the lowest As removal efficiencies (4\% and 2\%, respectively) compared to the milled SB and RH powders (20\% and $18 \%$, respectively), while the derived nanocelluloses had an efficiency of $43 \%$ and $47 \%$ respectively (Table S8). Likewise, the native $\mathrm{Fe}_{3} \mathrm{O}_{4}$ nanoparticles had an As removal efficiency of 69\% (Table S9). Thus, it can be concluded that the enhanced adsorption capacity of the synthesized NIONs may have resulted from the synergistic effect of nanocelluloses and $\mathrm{Fe}_{3} \mathrm{O}_{4}$ nanoparticles in the synthesized nanocomposite.

For the comparative assessment of As adsorption efficiency by the NIONs, it was evaluated against commercial adsorbents like activated carbon (Sigma Aldrich) and activated alumina (Sigma Aldrich) (Fig. 8b). Under the optimized experimental conditions employing 50ppb As, 52.5 gL ${ }^{-1}$ adsorbent, $\mathrm{pH}: 7$ and a contact time of $12 \mathrm{H}$, both $\mathrm{SB}$ and $\mathrm{RH}-\mathrm{NIONs}$ showed $\sim 73 \%$ and $\sim 42 \%$ removal efficiencies of activated carbon and activated alumina which is lower than As removal efficiency ( 99\%).

To validate the potential of the NIONs for practical applications, the As removal efficiency of the NIONs was also investigated under in vitro simulated-field conditions and groundwater samples collected from actual contamination sites. Since potable groundwater sources polluted with As are reported to suffer from co-contamination with other heavy metals, salts, anions and cations that interfere competitively with As removal, the in vitro simulated-field conditions were derived using standard solutions of prevailing heavy metals at concentrations recorded in earlier studies (Table S9) [53]. Both SB and RH-NIONs show only a minimal decline of 5\% to $9 \%$ in their As removal efficiencies when contaminated field samples were used (Fig. 8c). These findings suggest that the co-contaminants of As that are usually present in naturally contaminated groundwater, do not exert a significant influence on the adsorption capabilities of the NIONs. The adsorbents were also evaluated for their remediation abilities against the other commonly prevalent groundwater contaminants such as lead $(\mathrm{Pb})$, copper $(\mathrm{Cu})$, zinc $(\mathrm{Zn})$ and manganese $(\mathrm{Mn})$ under in vitro simulated-field conditions. The RH-NIONs showed a removal efficiency of $92 \%$ for $\mathrm{Pb}, 95 \%$ for $\mathrm{Zn}, 74 \%$ for $\mathrm{Cu}$ and $68 \%$ for $\mathrm{Mn}$, while $\mathrm{SB}$ NIONs showed removal efficiencies of $97 \%$ for $\mathrm{Pb}, 89 \%$ for $\mathrm{Zn}, 71 \%$ for $\mathrm{Cu}$ and $65 \%$ for Mn (Fig. 8d). 

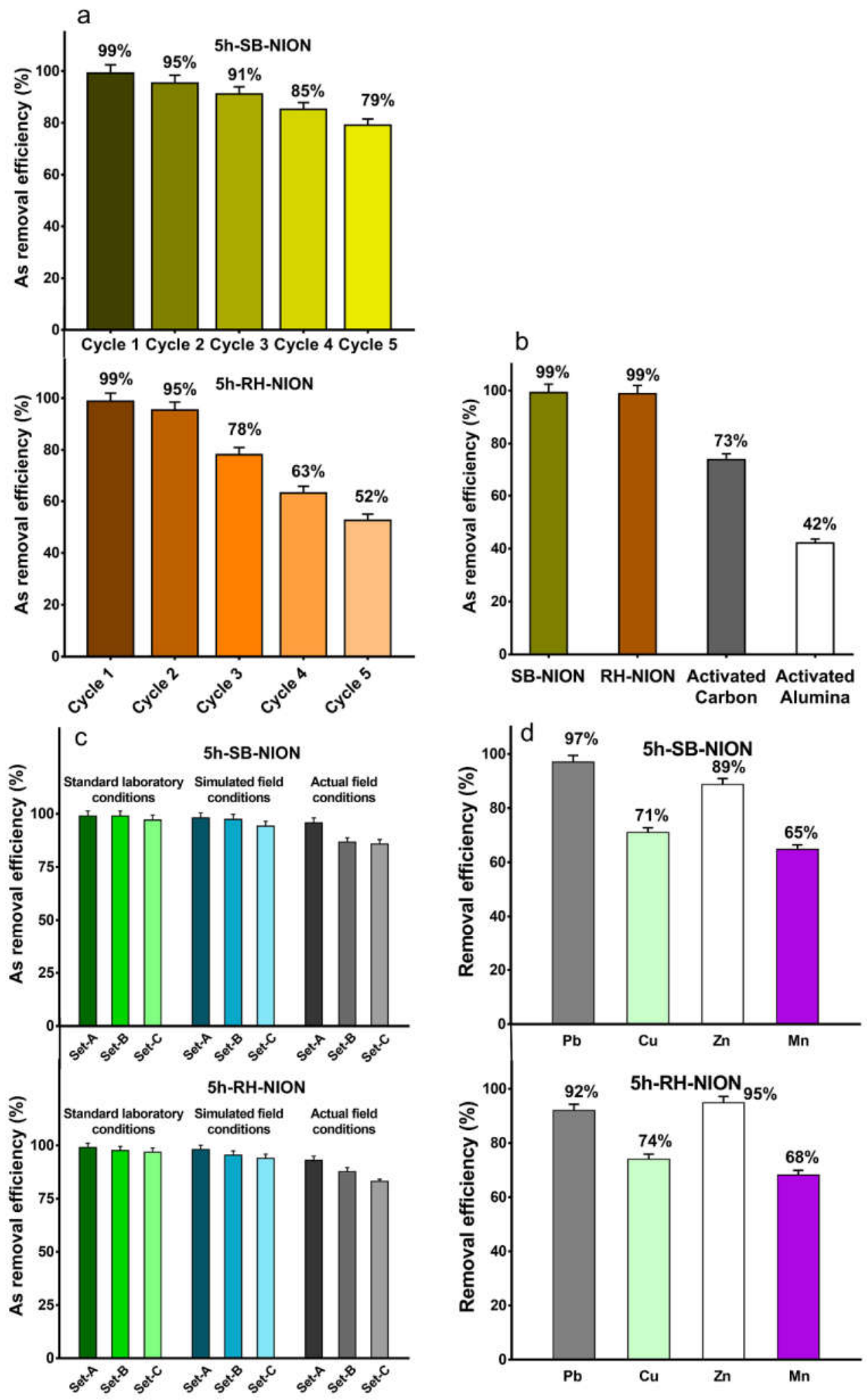
Fig. 8. Recyclability of the $5 \mathrm{~h}$ SB-NION and $5 \mathrm{~h}$ RH-NION for five successive readsorption cycles (a), comparison assessment of $5 \mathrm{~h}$ SB-NION and 5h RH-NION of the As removal efficiencies with commercial adsorbents, activated carbon and activated alumina (b), As removal efficiencies of the $5 \mathrm{~h}$ SB-NION and the $5 \mathrm{~h}$ RH-NION from standard As laboratory solution, simulated field condition of As in solution with other prevalent metals and actual contaminated groundwater samples (c), removal efficiencies of the $5 \mathrm{~h}$ SB - NION and the $5 \mathrm{~h}$ RH -NION for other heavy metals viz. Pb, $\mathrm{Cu}, \mathrm{Zn}$, and Mn commonly prevalent in groundwater (d).

\section{Conclusions}

Nanoscale iron-oxide impregnated agro-waste derived nanocellulose were synthesized, characterized, and analyzed for aqueous As (III) adsorption. The adsorptive performance of the synthesized NIONs were studied using CCD-based RSM models and MLP-based ANN models that have led to the finding of maximum As removal efficiency of $\sim 99 \%$ under the conditions of $\sim 52.5 \mathrm{ppb}$ As concentration, $\sim 50 \mathrm{gL}^{-1}$ adsorbent dosage at $\mathrm{pH}$ for a contact time of $12 \mathrm{~h}$ for both SB and RH-NIONs. Adsorption on both the adsorbents meet Sips isothermal equation following pseudo-secondorder kinetics that suggested chemisorption as the underlying mechanism. The high adsorptive capacity together with their economic synthesis indicated the potential of the adsorbents to be used for real-world applications.

\section{Declaration of competing interest}

The authors declare that they have no competing interests.

\section{Acknowledgments}

The authors wish to acknowledge DBT, Govt. of India, for the Research Grant (Grant No. BT/258/NE/TBP/2011), UGC for the Research Grant (TU/ Fin/MBBT/ 116/ 05/ 11-12/ 64), and DST-FIST. Author Chayanika Chaliha, would like to acknowledge DST, Govt. of India for her DST INSPIRE Junior Research Fellowship (IF-19064). The authors also acknowledge SAIC-Tezpur University, Tezpur, Assam and SAIF-North-Eastern Hill University, Shillong, Meghalaya, for the analytical assistance.

\section{References}

[1]. P. K. Ghosh, T. K. Maiti, K. Pramanik, S. K.Ghosh, S. Mitra, T. K. De, The role of arsenic resistant Bacillus aryabhattai MCC3374 in promotion of rice seedlings growth and alleviation of arsenic phytotoxicity, Chemosphere. 211 (2018) 407-419. https://doi.org/10.1016/j.chemosphere.2018.07.148.

[2]. M. B. Shakoor, N. K. Niazi, I. Bibi, M. Shahid, F. Sharif, S. Bashir, S. M. Shaheen, H. Wang, D. C. W. Tsang, Y. S. Ok, J. Rinklebe, Arsenic removal by natural and chemically modified watermelon rind in aqueous solutions and groundwater, Sci Total Environ. 645 (2018) $1444-1455$. https://doi.org/10.1016/j.scitotenv.2018.07.218.

[3]. R. Molinari, P. Argurio, Arsenic removal from water by coupling photocatalysis and complexation-ultrafiltration processes: a preliminary study, Water Res. 109 (2017) 327-336. https://doi.org/10.1016/j.watres.2016.11.054.

[4]. S. Lata, S. R. Samadder, Removal of arsenic from water using nano adsorbents and challenges: a review, J. Environ. Manage. 166 (2016) 387-406. https://doi.org/10.1016/j.jenvman.2015.10.039.

[5]. L. Hao, N. Wang, C. Wang, G. Li, Arsenic removal from water and river water by the combined adsorption-UF membrane process. Chemosphere, 202 (2018) 768-776. https://doi.org/10.1016/j.chemosphere.2018.03.159. 
[6]. P. Song, Z. Yang, G. Zeng, X. Yang, H. Xu, L. Wang, R. Xu, W. Xiong, K. Ahmad, Electrocoagulation treatment of arsenic in wastewaters: a comprehensive review, Chem. Eng. J. 317 (2017) 707-725. https://doi.org/10.1016/j.cej.2017.02.086.

[7]. W. Tang, Y. Su, Q. Li, S. Gao, J. K. Shang, Superparamagnetic magnesium ferrite nanoadsorbent for effective arsenic (III, V) removal and easy magnetic separation, Water Res. 47 (2013) 3624-3634. https://doi.org/10.1016/j.watres.2013.04.023.

[8]. J. E. Greenleaf, J. C. Lin, A. K. Sengupta, Two novel applications of ion exchange fibers: Arsenic removal and chemical- free softening of 373 hard water, Environ. Prog. 25 (2006) 300-311. https://doi.org/10.1002/ep.10163.

374 [9]. P. C. Okafor, P. U. Okon, E. F. Daniel, E. E. Ebenso, Adsorption capacity of coconut (Cocos nucifera L.) shell for lead, copper, cadmium, and 375 arsenic from aqueous solutions. Int. J. Electrochem. Sci. 7 (2012) 12354-12369.

376 [10]. L. Pontoni, M. Fabbricino, Use of chitosan and chitosan-derivatives to remove arsenic from aqueous solutions-a mini review, Carbohydr. 377 Res. 356 (2012) 86-92. https://doi.org/10.1016/j.carres.2012.03.042.

378 [11]. K. Xie, L. Jing, W. Zhao, Y. Zhang, Adsorption removal of $\mathrm{Cu}^{2+}$ and $\mathrm{Ni}^{2+}$ from waste water using nano- cellulose hybrids containing 379 reactive polyhedral oligomeric silsesquioxanes, J. Appl. Polym. Sci. 122 (2011) 2864-2868. https://doi.org/10.1002/app.34411

[12]. M. Ghanbarian, R. Nabizadeh, S. Nasseri, F. Shemirani, A. H. Mahvi, M. H. Beyki, A. Mesdaghinia, Potential of amino-riched nanostructured MnFe2O4@ cellulose for biosorption of toxic Cr (VI): modeling, kinetic, equilibrium and comparing studies. Int. J. Biol.

Macromol. 104 (2017) 465-480. https://doi.org/10.1016/j.ijbiomac.2017.06.060

[13]. X. Luo, X. Lei, N. Cai, X. Xie, Y. Xue, F. Yu, Removal of heavy metal ions from water by magnetic cellulose-based beads with embedded chemically modified magnetite nanoparticles and activated carbon, ACS Sustain. Chem. Eng. 4 (2016) 3960-3969.

https://doi.org/10.1021/acssuschemeng.6b00790

[14]. Y. Q. Zheng, S. Deng, L. Niu, F. J. Xu, M. Y. Chai, G. Yu, Functionalized cotton via surface-initiated atom transfer radical polymerization for enhanced sorption of $\mathrm{Cu}$ (II) and Pb (II), J. Hazard. Mater. 192 (2011) 1401-1408. https://doi.org/10.1016/j.jhazmat.2011.06.054

[15]. M. Tian, L. Qu, X. Zhang, K. Zhang, S. Zhu, X. Guo, G. Han, X. Tang, Y. Sun, Enhanced mechanical and thermal properties of regenerated cellulose/graphene composite fibers, Carbohydr. Polym. 111 (2014) 456-462. https://doi.org/10.1016/j.carbpol.2014.05.016

[16]. D. Roy, M. Semsarilar, J. T. Guthrie, S. Perrier, Cellulose modification by polymer grafting: a review, Chem. Soc. Rev. 38 (2009). 20462064. https://doi.org/10.1039/B808639G

[17]. T. S. Anirudhan, F. Shainy, Effective removal of mercury (II) ions from chlor-alkali industrial wastewater using 2-mercaptobenzamide modified itaconic acid-grafted-magnetite nanocellulose composite, J. Colloid Interface Sci. 456 (2015) 22-31.

https://doi.org/10.1016/j.jcis.2015.05.052

[18]. M. T. Islam, M. M. Alam, A. Patrucco, A. Montarsolo, M. Zoccola, Preparation of nanocellulose: A review, AATCC J. Res. 1 (2014) 17-23. https://doi.org/10.14504/ajr.1.5.3 
[19]. K. Gupta, A. Kaushik, K. B. Tikoo, V. Kumar, S. Singhal, Enhanced catalytic activity of composites of NiFe2O4 and nano cellulose derived

from waste biomass for the mitigation of organic pollutants, Arab. J. Chem. 13 (2017) 783-798. https://doi.org/10.1016/j.arabjc.2017.07.016

[20]. P. Z. Ray, H. J. Shipley, Inorganic nano-adsorbents for the removal of heavy metals and arsenic: a review, RSC Adv. 5 (2015) 29885-

29907. https://doi.org/10.1039/C5RA02714D.

401 [21]. P. R. Sharma, A. Chattopadhyay, S. K. Sharma, B. S. Hsiao, Efficient removal of $\mathrm{UO}_{2}{ }^{2+}$ from water using carboxy cellulose nanofibers prepared by the nitro-oxidation method. Ind. Eng. Chem. Res. 56 (2017) 13885-13893. https://doi.org/10.1021/acs.iecr.7b03659.

[22]. P. R. Sharma, A. Chattopadhyay, S. K. Sharma, L. Geng, N. Amiralian, D. Martin, B. S. Hsiao, Nanocellulose from spinifex as an effective adsorbent to remove cadmium (II) from water. ACS Sustain. Chem. Eng. 6 (2018) 3279-3290. https://doi.org/10.1021/acssuschemeng.7b03473.

[23]. P. R. Sharma, A. Chattopadhyay, C. Zhan, S. K. Sharma, L. Geng, B. S. Hsiao, Lead removal from water using carboxy cellulose nanofibers prepared by nitro-oxidation method, Cellulose. 25 (2018) 1961-1973. https://doi.org/10.1007/s10570-018-1659-9

[24]. P. R. Sharma, S. K. Sharma, R. Antoine, B. S. Hsiao, Efficient removal of arsenic using zinc oxide nanocrystal-decorated regenerated microfibrillated cellulose scaffolds. ACS Sustain. Chem. Eng. 7 (2019) 6140-6151. https://doi.org/10.1021/acssuschemeng.8b06356.

[25]. J. Wei, Z. Yang, Y. Sun, C. Wang, J. Fan, G. Kang, R. Zhang, S. Dong, Y. Li, Nanocellulose-based magnetic hybrid aerogel for adsorption of heavy metal ions from water, J. Mater. Sci. 54 (2019) 6709-6718. https://doi.org/10.1007/s10853-019-03322-0

[26]. S. Zarei, M. Niad, H. Raanaei, The removal of mercury ion pollution by using Fe3O4-nanocellulose: Synthesis, characterizations and DFT studies, J. Hazard. Mater. 344 (2018) 258-273. https://doi.org/10.1016/j.jhazmat.2017.10.009

[27]. K. A. Taleb, J. D. Rusmirović, M. P. Rančić, J. B. Nikolić, S. Ž. Drmanić, Z. S. Veličković, A. D. Marinković, Efficient pollutants removal by amino-modified nanocellulose impregnated with iron oxide. J. Serb. Chem. Soc. 81 (2016) 1199-1213.

https://doi.org/10.2298/JSC160529063T

[28]. J. Baruah, R. C. Deka, E. Kalita, Greener production of microcrystalline cellulose (MCC) from Saccharum spontaneum (Kans grass):

Statistical optimization, Int. J Biol. Macromol. 154 (2020) 672-682. https://doi.org/10.1016/j.ijbiomac.2020.03.158

[29]. G. E. Box, K. B. Wilson, On the experimental attainment of optimum conditions, J R Stat. Soc. B. 13 (1951) 1-38. https://doi.org/10.1111/j.2517-6161.1951.tb00067.x.

[30]. S. L. C. Ferreira, R. E. Bruns, E. G. P. a Silva, W. N. L. Dos Santos, C. M. Quintella, J. M. David, J. B. de Andrade, M. C. Breitkreitz, I. C. S. F. Jardim, B. B. Neto, Statistical designs and response surface techniques for the optimization of chromatographic systems, J. Chromatogr. A. 1158 (2007) 2-14. https://doi.org/10.1016/j.chroma.2007.03.051.

[31]. R. H. Myers, D. C. Montgomery, C. M. Anderson-Cook, Response surface methodology: process and product optimization using designed experiments, fourth ed., John Wiley \& Sons, Inc., Hoboken, New Jersey, 2016. 
[32]. G. Hasani, H. Daraei, B. Shahmoradi, F. Gharibi, A. Maleki, K. Yetilmezsoy, G. McKay, A novel ANN approach for modeling of alternating pulse current electrocoagulation-flotation (APC-ECF) process: Humic acid removal from aqueous media, Proc. Saf. Environ. 117 (2018) $111-124$. https://doi.org/10.1016/j.psep.2018.04.017.

[33]. F. Geyikçi, E. Kılıç, S. Çoruh, S. Elevli, Modeling of lead adsorption from industrial sludge leachate on red mud by using RSM and ANN, Chem. Eng. J. 183 (2012) 53-59. https://doi.org/10.1016/j.cej.2011.12.019.

[34]. M. Massoudinejad, M. Ghaderpoori, A. Shahsavani, A. Jafari, B. Kamarehie, A. Ghaderpoury, M. M. Amini, Ethylenediaminefunctionalized cubic ZIF-8 for arsenic adsorption from aqueous solution: Modeling, isotherms, kinetics, and thermodynamics, J. Mol. Liq. 255 (2018) 263-268. https://doi.org/10.1016/j.molliq.2018.01.163.

[35]. N. Ghaemi, S. Zereshki, S. Heidari, Removal of lead ions from water using PES-based nanocomposite membrane incorporated with polyaniline modified GO nanoparticles: Performance optimization by central composite design, Proc. Saf. Environ. 111 (2017) 475-490. https://doi.org/10.1016/j.psep.2017.08.011.

[36]. B. Nagy, C. Mânzatu, A. Măicăneanu, C. Indolean, L. Barbu-Tudoran, C. Majdik, Linear and nonlinear regression analysis for heavy metals removal using Agaricus bisporus macrofungus, Arab. J. Chem. 10 (2017) S3569-S3579. https://doi.org/10.1016/j.arabjc.2014.03.004.

[37]. J. Ma, Z. Zhu, B. Chen, M. Yang, H. Zhou, C. Li, F. Yu, J. Chen, One-pot, large-scale synthesis of magnetic activated carbon nanotubes and their applications for arsenic removal. J. Mater. Chem. A. 1 (2013) 4662-4666. https://doi.org/10.1039/C3TA10329C.

[38]. N. T. A. Thu, N. D. Cuong, D. Q. Khieu, P. C. Nam, N. Van Toan, C. M. Hung, N. Van Hieu, $\mathrm{Fe}_{2} \mathrm{O}_{3}$ nanoporous network fabricated from $\mathrm{Fe}_{3} \mathrm{O}_{4} /$ reduced graphene oxide for high-performance ethanol gas sensor, Sensor. Actuat. B- Chem. 255 (2018) $3275-3283$. https://doi.org/10.1016/j.snb.2017.09.154.

[39]. B. K. Nath, C. Chaliha, E. Kalita, M. C. Kalita, Synthesis and characterization of ZnO: CeO2: nanocellulose: PANI bionanocomposite. A bimodal agent for arsenic adsorption and antibacterial action, Carbohydr. Polym. 148 (2016) 397-405. https://doi.org/10.1016/j.carbpol.2016.03.091.

[40]. N. Habibi, Preparation of biocompatible magnetite-carboxymethyl cellulose nanocomposite: characterization of nanocomposite by FTIR, XRD, FESEM, and TEM, Spectrochim. Acta A. 131 (2014) 55-58. https://doi.org/10.1016/j.saa.2014.04.039.

[41]. S. Lin, D. Lu, Z. Liu, Removal of arsenic contaminants with magnetic $\gamma-\mathrm{Fe}_{2} \mathrm{O}_{3}$ nanoparticles, Chem. Eng. J. 211 (2012) $46-52$. https://doi.org/10.1016/j.cej.2012.09.018.

[42]. A. Baykal, M. Amir, S. Günerb, H. Sözeri, Preparation and characterization of SPION functionalized via caffeic acid, J. Magn. Magn.

Mater. 395 (2015) 199-204. https://doi.org/10.1016/j.jmmm.2015.07.095. 
[43]. D. K. Verma, S. H. Hasan, D. K. Singh, S. Singh, Y. Singh, Enhanced biosorptive remediation of hexavalent chromium using chemotailored biomass of a novel soil isolate Bacillus aryabhattai ITBHU02: process variables optimization through artificial neural network linked genetic algorithm, Ind. Eng. Chem. Res. 53 (2014) 3669-3681. https://doi.org/10.1021/ie404266k.

[44]. B. K. Nath, C. Chaliha, E. Kalita, Iron oxide Permeated Mesoporous rice-husk nanobiochar (IPMN) mediated removal of dissolved arsenic (As): Chemometric modeling and adsorption dynamics. J. Env. Manage. 246 (2019) 397-409. https://doi.org/10.1016/j.jenvman.2019.06.008.

457 [45]. B. Liao, W. Y. Sun, N. Guo, S. L. Ding, S. J. Su, Comparison of Co ${ }^{2+}$ adsorption by chitosan and its triethylene-tetramine derivative: 458 Performance and mechanism, Carbohydr. Polym. 151 (2016) 20-28. https://doi.org/10.1016/j.carbpol.2016.05.053. wastewater, Chemosphere. 138 (2015) 462-468. https://doi.org/10.1016/j.chemosphere.2015.06.085.

[47]. V. K. Gupta, P. J. M. Carrott, R. Singh, M. Chaudhary, S. Kushwaha, Cellulose: a review as natural, modified and activated carbon adsorbent, Biores. Technol. 216 (2016) 1066-1076. https://doi.org/10.1016/j.biortech.2016.05.106.

[48]. L. Huo, X. Zeng, S. Su, L. Bai, Y. Wang, Enhanced removal of As (V) from aqueous solution using modified hydrous ferric oxide nanoparticles, Sci. Rep. 7 (2017) 40765. https://doi.org/10.1038/srep40765.

[49]. S. Zarei, M. Niad, H. Raanaei, The removal of mercury ion pollution by using $\mathrm{Fe}_{3} \mathrm{O}_{4}$-nanocellulose: Synthesis, characterizations and DFT studies, J. Hazard. Mater. 344 (2018) 58-273. https://doi.org/10.1016/j.jhazmat.2017.10.009.

[50]. X. Guo, Y. Du, F. Chen, H. S. Park, Y. Xie, Mechanism of removal of arsenic by bead cellulose loaded with iron oxyhydroxide ( $\beta$-FeOOH): EXAFS study, J. Colloid. Interface. Sci. 314 (2007) 427-433. https://doi.org/10.1016/j.jcis.2007.05.071.

[51]. X. Yu, S. Tong, M. Ge, J. Zuo, C. Cao, W. Song, One-step synthesis of magnetic composites of cellulose@ iron oxide nanoparticles for arsenic removal. J. Mat. Chem. A. 1 (2013) 959-965. https://doi.org/10.1039/C2TA00315E.

[52]. Q. Xue, Y. Ran, Y. Tan, C. L. Peacock, H. Du, Arsenite and arsenate binding to ferrihydrite organo-mineral coprecipitate: Implications for arsenic mobility and fate in natural environments, Chemosphere. 224 (2019) 103-110. https://doi.org/10.1016/j.chemosphere.2019.02.118.

[53]. B. K. Nath, C. Chaliha, B. Bhuyan, E. Kalita, D. C. Baruah, A. K. Bhagabati, GIS mapping-based impact assessment of groundwater contamination by arsenic and other heavy metal contaminants in the Brahmaputra River valley: A water quality assessment study, J. Clean. Prod. 201 (2018) 1001-1011. https://doi.org/10.1016/j.jclepro.2018.08.084. 
Modelling and optimization of factors influencing adsorptive performance of agrowastederived Nanocellulose/Iron Oxide Nanobiocomposites during remediation of Arsenic contaminated groundwater

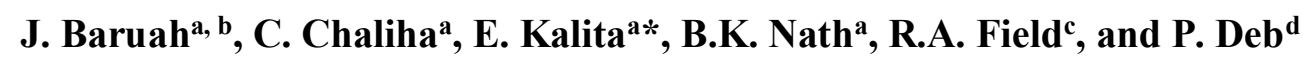

${ }^{\text {a} D e p a r t m e n t ~ o f ~ M o l e c u l a r ~ B i o l o g y ~ a n d ~ B i o t e c h n o l o g y, ~ T e z p u r ~ U n i v e r s i t y, ~ T e z p u r, ~ A s s a m, ~}$ 784028, India

${ }^{\mathrm{b}}$ Department of Chemical Sciences, Tezpur University, Tezpur, Assam, 784028, India

${ }^{\mathrm{c}}$ Department of Chemistry and Manchester Institute of Biotechnology The University of manchester 131 Princess Street, Manchester M1 7DN (UK)

${ }^{\mathrm{d} D e p a r t m e n t ~ o f ~ P h y s i c s, ~ T e z p u r ~ U n i v e r s i t y, ~ T e z p u r, ~ A s s a m, ~ 784028, ~ I n d i a ~}$

*Correspondence:

Dr. Eeshan Kalita

ekalita@tezu.ernet.in 


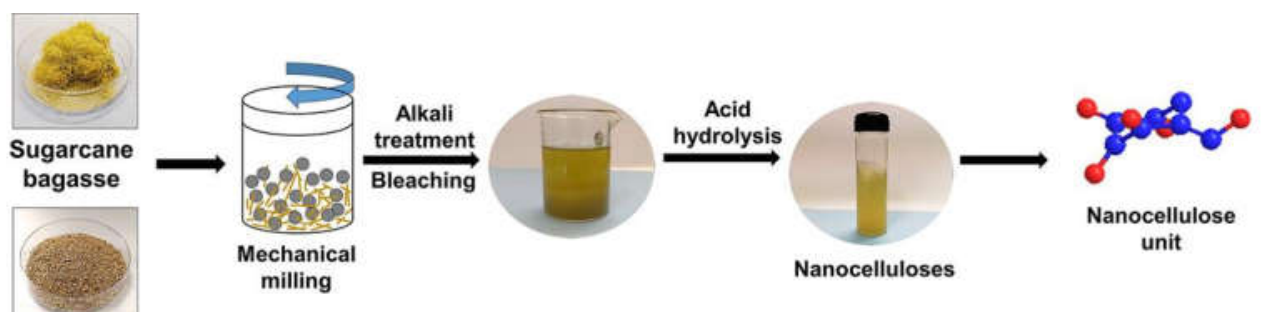

Rice husk

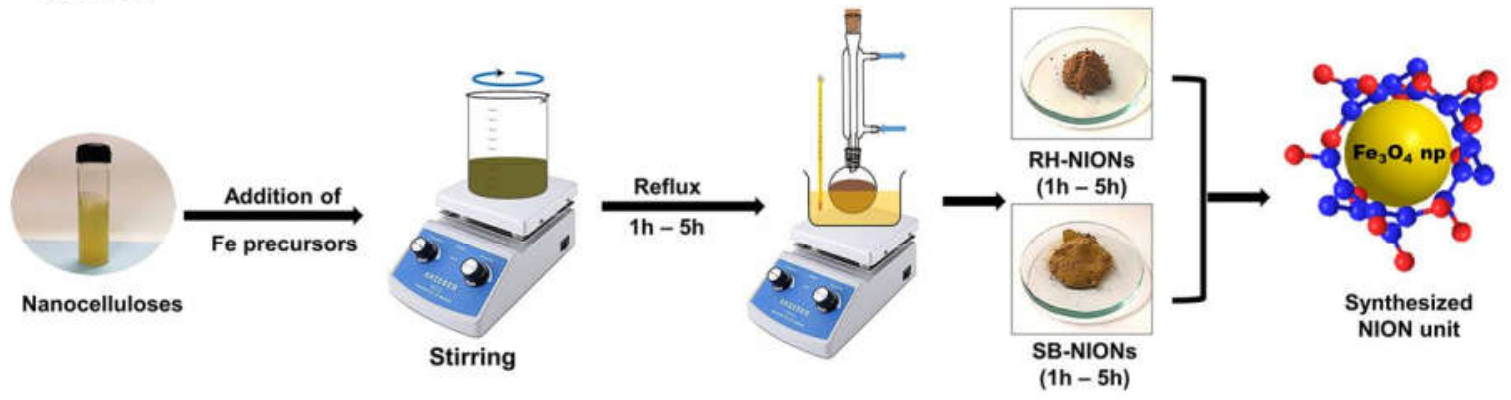

Solvothermal synthesis of SB and RH-NION variants

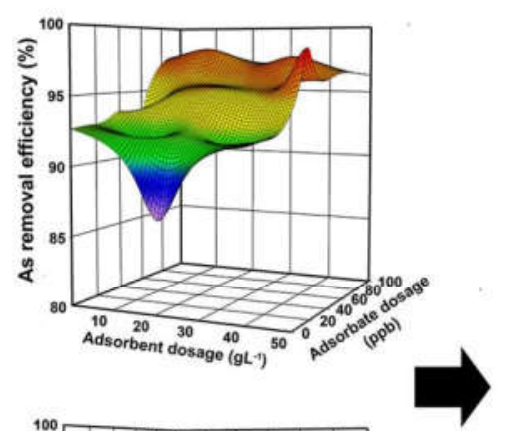

SB-NION
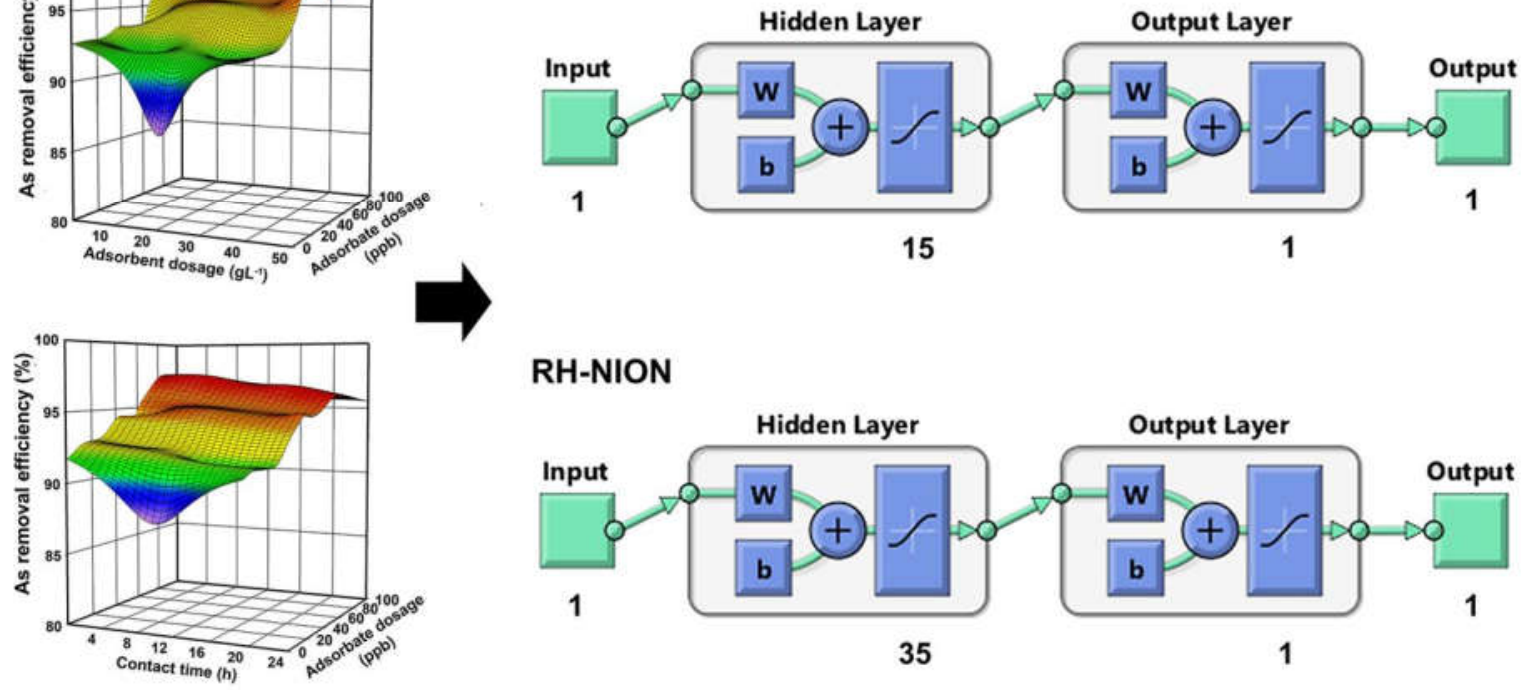

RH-NION

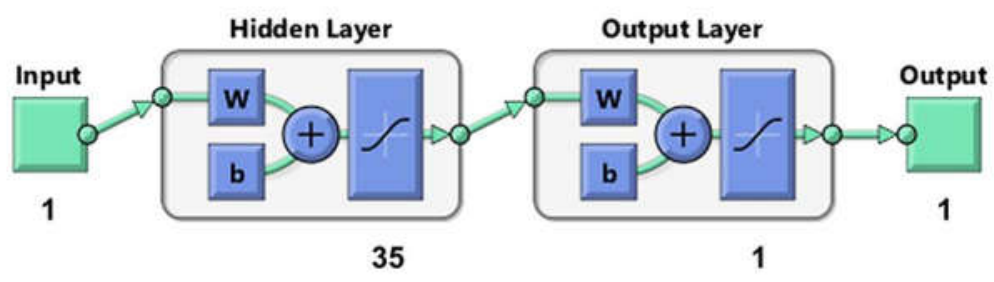

Influence of parametric interactions on As adsorption using RSM and ANN

Fig. 1. Schematic representation of the synthesis and optimization of SB and RH-NIONs for the removal of As. 

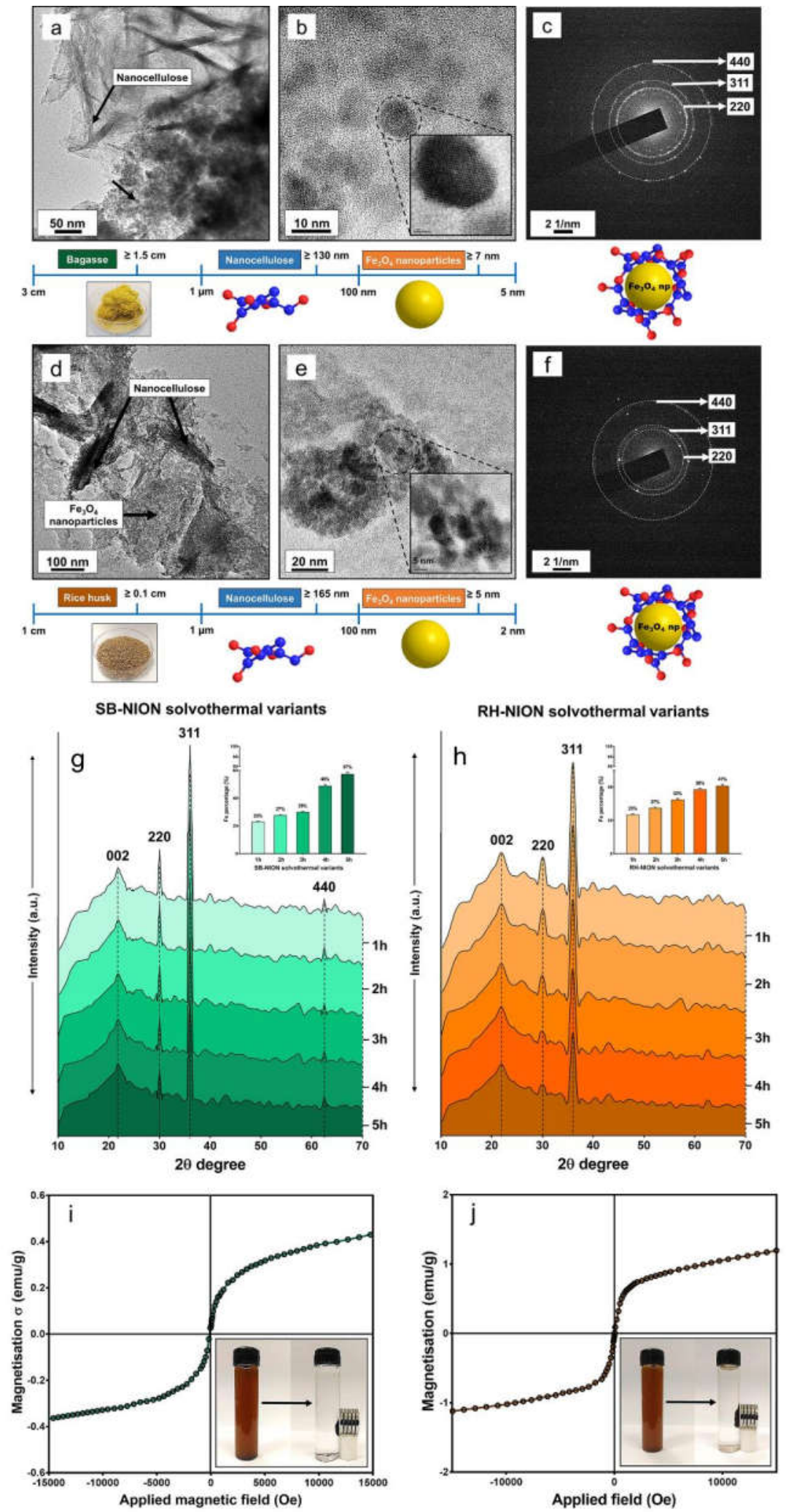
Fig. 2. TEM micrographs of the SB-NION ( $a, b)$ and RH-NION (d, e) with scale diagrams of precursor materials, derived nanocellulose and $\mathrm{Fe}_{3} \mathrm{O}_{4}$ NPs, selected area electron diffraction (SAED) patterns of the SB-NION (c) and RH-NION (f); comparative X-ray diffractograms of the synthesized SB-NION solvothermal variants (g) and the RH-NION solvothermal variants (h); Fe content (\%) of the synthesized SB-NIONs (g inset) and RH-NIONs (h inset); magnetic hysteresis (M-H) curve for the synthesized SB-NION (i) and RH-NION (j) and magnetic recovery of SBNION (i inset) and RH-NION ( $\mathrm{j}$ inset) in As solution under the influence of external magnetic field (214 Gauss). 
Impact of adsorption parameters
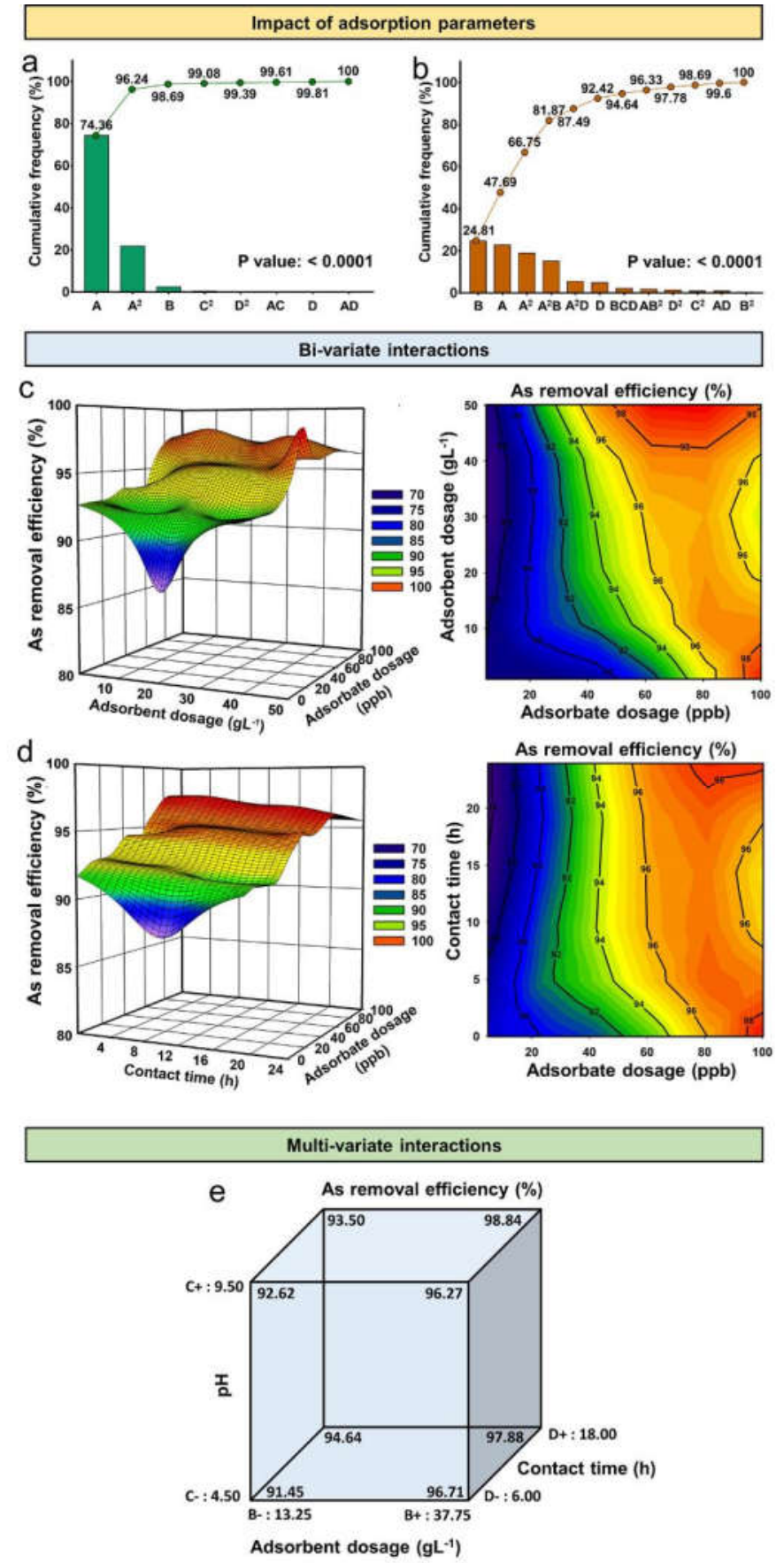

Fig. 3. Pareto chart showing the impact of various experimental parameters in the adsorption of As by the 5h SB-NION (a) and RH-NION (b); effect of bi-variate interactions on the adsorption of As by the 5h RH-NION (c, d); cubic plot showing the effect of multi-variate interactions on the adsorption of As by the 5h RH-NION (e) as described by the CCD matrices of RSM. 

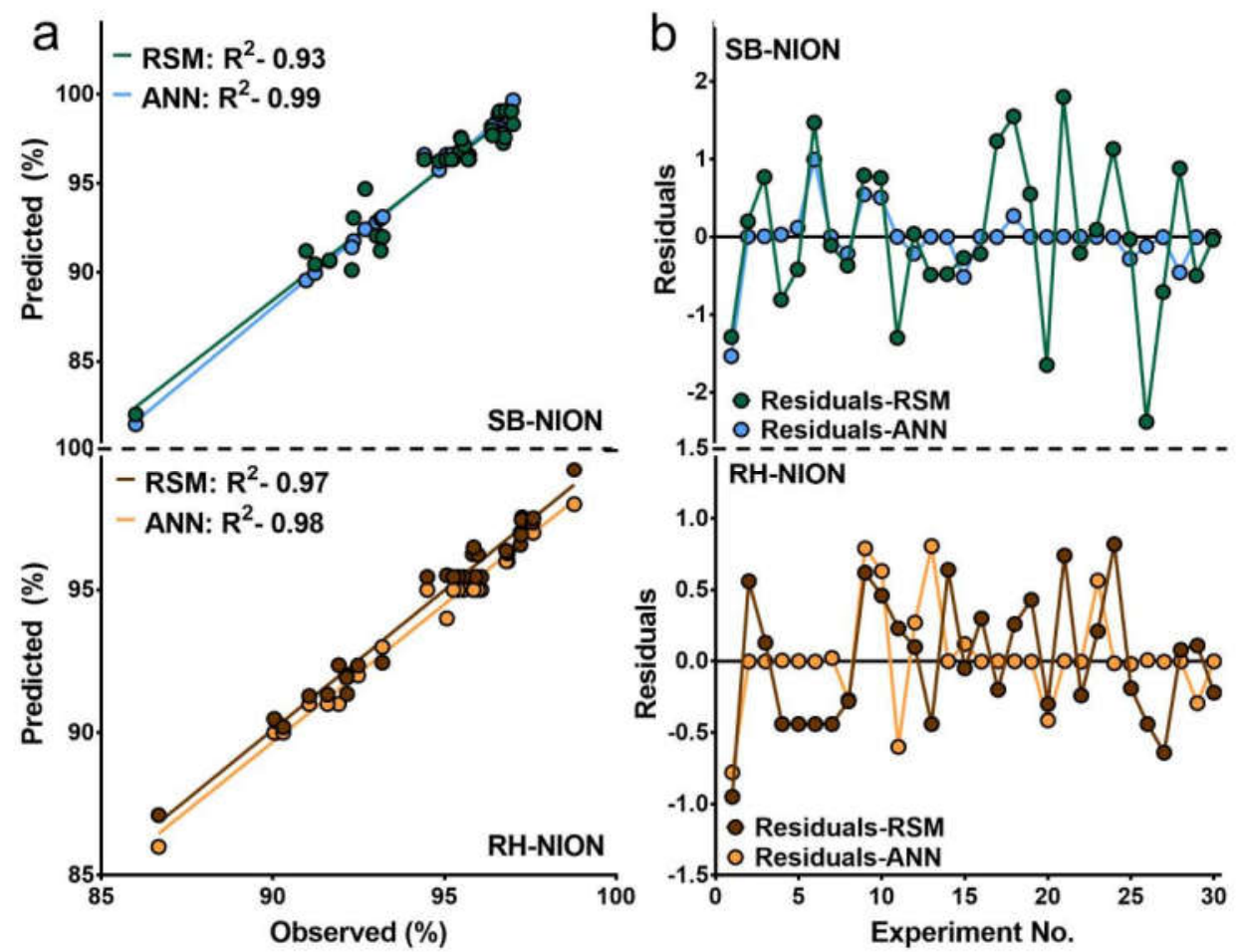

Fig. 4. Comparison of predictive outputs of RSM and ANN-based chemometric models on the basis of determination coefficient (a) and distribution of residuals (b) for the adsorption of As by the $5 \mathrm{~h}$ SB-NION and $5 \mathrm{~h}$ RH-NION. 

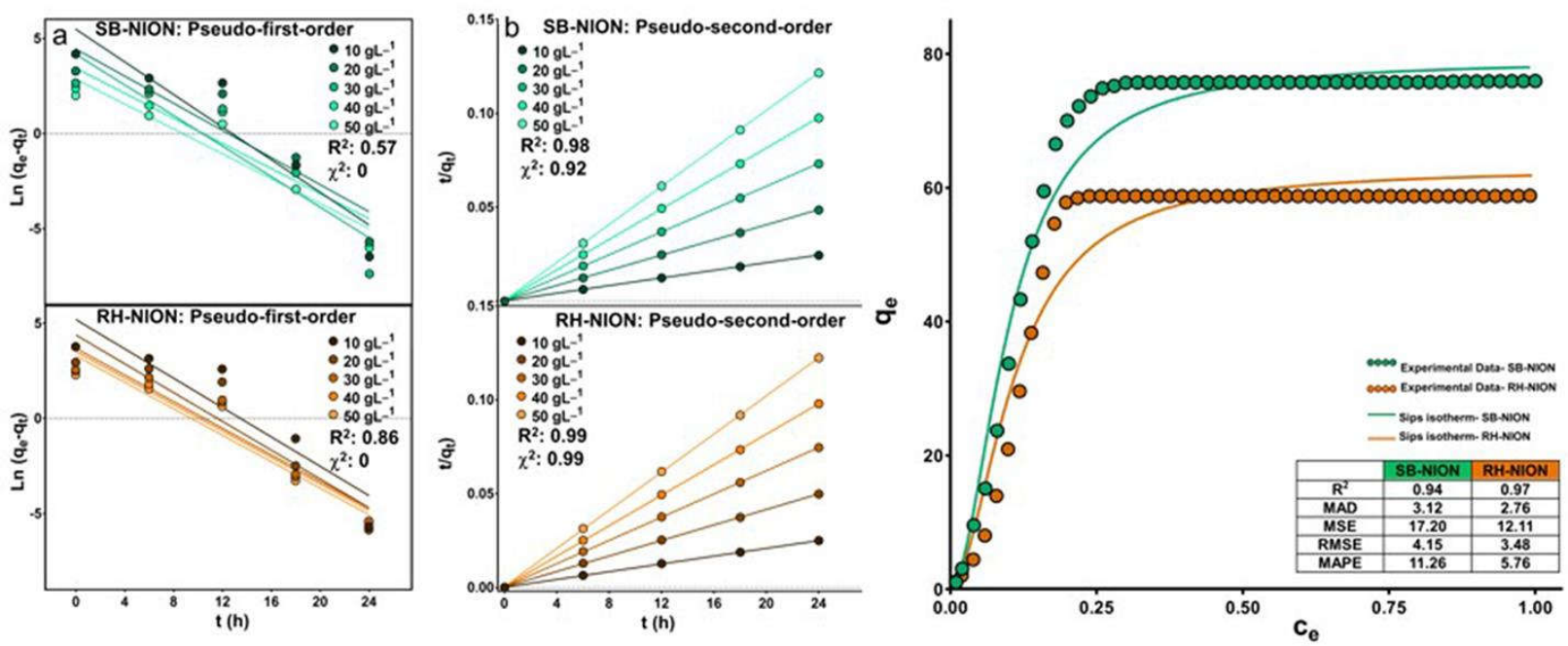

Fig. 5. Pseudo-first-order (a), pseudo-second-order (b) adsorption kinetics curves and non-linear fits of Sips adsorption isotherm plot for the adsorption of As by the SB-NION and the RH-NION (c). 

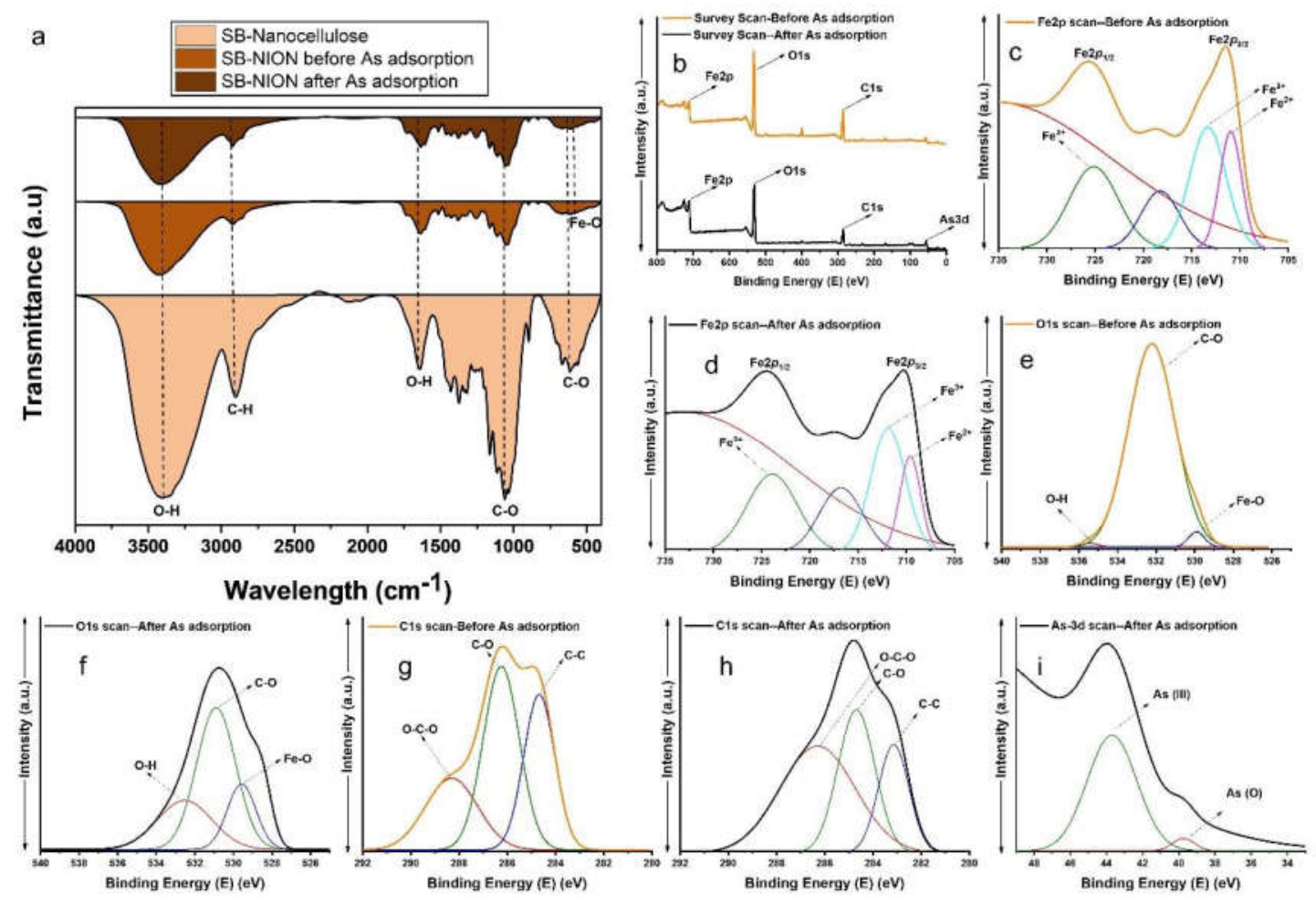

Fig. 6. Comparative FTIR spectra of the SB- nanocellulose, SB-NION before adsorption and SBNION after adsorption (a); XPS-survey scan of the SB-NION before and after As adsorption (b); Fe (2p) XPS spectra (c, d); O (1s) XPS spectra (e, f); C (1s) XPS spectra (g, h); before and after As adsorption and As (3d) XPS spectra (i) after the adsorption of As by the SB-NION. 


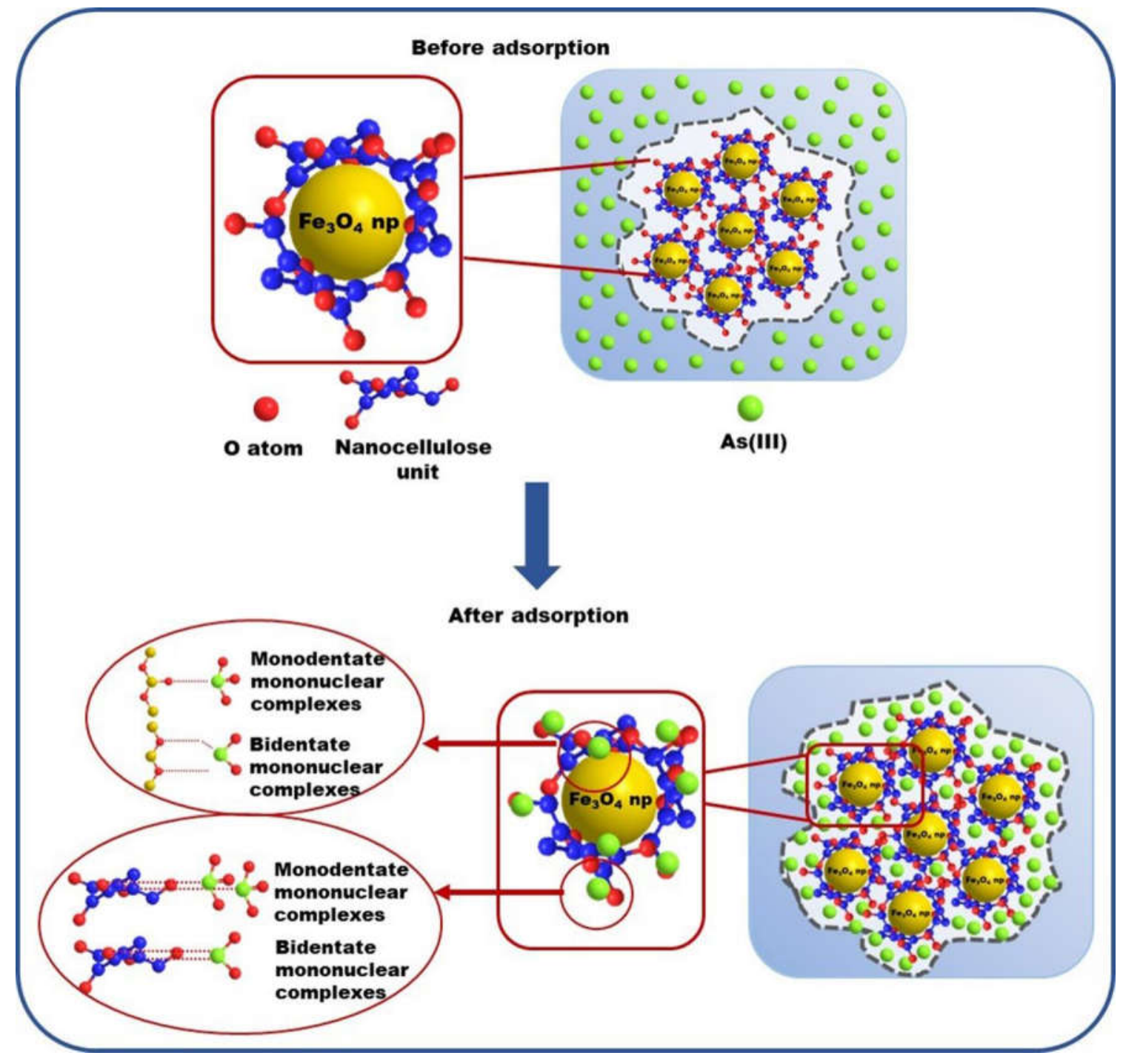

Fig. 7. Probable mechanism for As adsorption by the NIONs, based on XPS and FT-IR spectroscopic studies. 

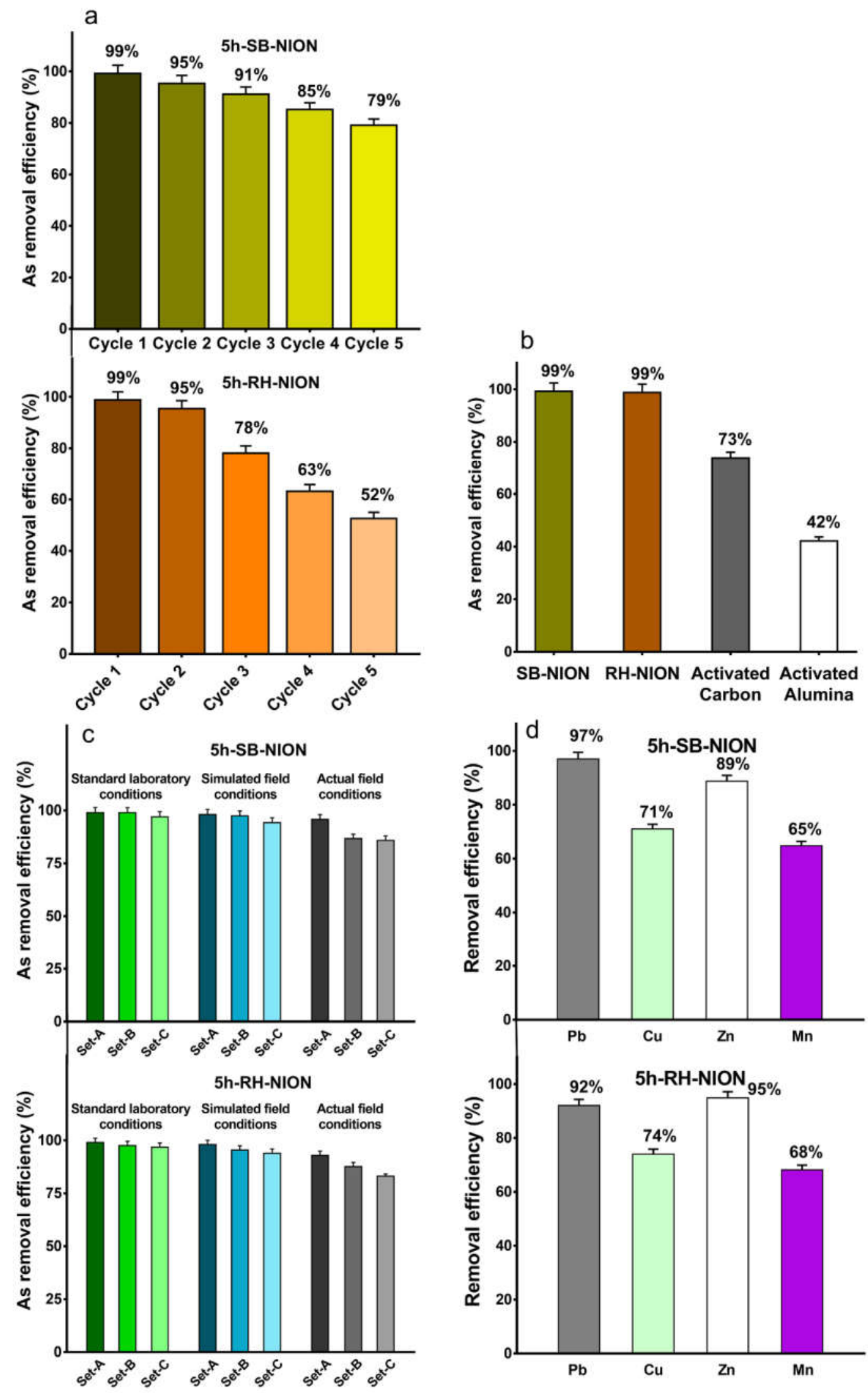
Fig. 8. Recyclability of the $5 \mathrm{~h}$ SB-NION and 5h RH-NION for five successive readsorption cycles (a), comparison assessment of 5h SB-NION and 5h RH-NION of the As removal efficiencies with commercial adsorbents, activated carbon and activated alumina (b), As removal efficiencies of the 5h SB-NION and the 5h RH-NION from standard As laboratory solution, simulated field condition of As in solution with other prevalent metals and actual contaminated groundwater samples (c), removal efficiencies of the $5 \mathrm{~h}$ SB -NION and the $5 \mathrm{~h}$ RH -NION for other heavy metals viz. $\mathrm{Pb}$, $\mathrm{Cu}, \mathrm{Zn}$ and Mn commonly prevalent in groundwater (d). 
Modelling and optimization of factors influencing adsorptive performance of agrowaste-derived Nanocellulose/Iron Oxide Nanobiocomposites during remediation of Arsenic contaminated groundwater

J. Baruaha, ${ }^{a}$, C. Chaliha ${ }^{a}$, E. Kalita ${ }^{a *}$, B.K. Nath ${ }^{a}$, R.A. Field ${ }^{c}$ and P. Deb ${ }^{d}$

aDepartment of Molecular Biology and Biotechnology, Tezpur University, Tezpur, Assam, 784028, India

bepartment of Chemical Sciences, Tezpur University, Tezpur, Assam, 784028, India

'Department of Chemistry and Manchester Institute of Biotechnology The University of manchester 131 Princess Street, Manchester M1 7DN (UK)

${ }^{\mathrm{d}}$ Department of Physics, Tezpur University, Tezpur, Assam, 784028, India

*Correspondence:

Dr. Eeshan Kalita

ekalita@tezu.ernet.in

CRediT authorship contribution statement

Julie Baruah: Investigation, Methodology, Formal analysis, Data curation, Writing - original draft. Chayanika Chaliha: Software, Formal Analysis, Data curation. Eeshan Kalita: Conceptualization, Methodology, Supervision, Writing - review \& editing, Project administration, Funding acquisition. Bikash Kar Nath: Investigation, Formal analysis. Robert A. Field: Conceptualization, Supervision. Pritam Deb: Validation, Resources, Writing - review \& editing 
Click here to access/download Supplementary Material Supplementary Data.docx 